\title{
Development of Zinc Oxide Piezoelectric Nanogenerators for Low Frequency Applications
}

\author{
Eiman Satti Nour
}

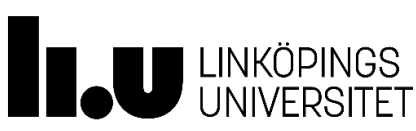

Department of Science and Technology (ITN)

Linköping University, Norrköping, Sweden.

$$
\text { Linköping } 2016 .
$$




\title{
Development of Zinc Oxide Piezoelectric Nanogenerators for Low Frequency Applications
}

\author{
Eiman Satti Nour
}

During the course of the research underlying this thesis, Eiman Nour was enrolled in Agora Materiae, a multidisciplinary doctoral program at Linköping University, Sweden.

Linköping Studies in Science and Technology.

The cover of the thesis shows the mechanical pressure exerted on the paper platform while handwriting is harvested to deliver electric energy by the $\mathrm{ZnO}$ NW/ polymer based nanogenerator. Cover by Eiman Satti Nour.

Printed by LiU-Tryck, Linköping, Sweden, 2016.

Dissertations. No. 1787

ISBN: 978-91-7685-693-2

ISSN: 0345-7524

Copyright (C) Eiman Satti Nour 2016.

eiman.satti.osman@liu.se

eiman_satti@hotmail.com 


\section{Dedication}

I would like to dedicate this dissertation to my family who has supported me all the way since the beginning of my skidies. Also, this dissertation is dedicated to my teachers and friends who have been a great source of motivation and inspiration. 



\begin{abstract}
Energy harvesting using piezoelectric nanomaterials provides an opportunity for advancement towards self-powered systems. Self-powered systems are a new emerging technology, which allows the use of a system or a device that perform a function without the need for external power source like for example, a battery or any other type of source. This technology can for example use harvested energy from sources around us such as ambient mechanical vibrations, noise, and human movement, etc. and convert it to electric energy using the piezoelectric effect. For nanoscale devices, the size of traditional batteries is not suitable and will lead to loss of the concept of "nano". This is due to the large size and the relatively large magnitude of the delivered power from traditional sources. The development of a nanogenerator (NG) to convert energy from the environment into electric energy would facilitate the development of some self-powered systems relying on nano- devices.

The main objective of this thesis is to fabricate a piezoelectric Zinc Oxide $(\mathrm{ZnO}) \mathrm{NGs}$ for low frequency $(<100 \mathrm{~Hz})$ energy harvesting applications. For that, different types of NGs based on $\mathrm{ZnO}$ nanostructures have been carefully developed, and studied for testing under different kinds of low frequency mechanical deformations. Well aligned $\mathrm{ZnO}$ nanowires (NWs) possessing high piezoelectric coefficient were synthesized on flexible substrates using the low temperature hydrothermal route. These $\mathrm{ZnO}$ NWs were then used in different configurations to demonstrate different low frequency energy harvesting devices.

Using piezoelectric $\mathrm{ZnO}$ NWs, we started with the fabrication of sandwiched NG for hand writing enabled energy harvesting device based on a thin silver layer coated paper substrate. Such device configurations can be used for the development of electronic programmable smart paper. Further, we developed this NG to work as a triggered sensor for wireless system using foot-step pressure. These studies demonstrate the feasibility of using $\mathrm{ZnO}$ NWs piezoelectric NG as a low-frequency self-powered sensor, with potential applications in wireless sensor networks. After that, we investigated and fabricated a sensor on PEDOT: PSS plastic substrate either by one side growth technique or by using double sided growth. For the first growth technique, the fabricated NG has been used as a sensor for acceleration system; while the fabricated NG by the second technique has worked as anisotropic directional sensor. This fabricated configurations showed stability for sensing and can be used in surveillance, security, and auto-mobil applications. In addition to that, we investigated the fabrication of a sandwiched $\mathrm{NG}$ on plastic substrates. Finally, we demonstrated that doping $\mathrm{ZnO}$ NWs with extrinsic element (such as $\mathrm{Ag}$ ) will lead to the reduction of the piezoelectric effect due to the loss of crystal symmetry. A brief summary into future opportunities and challenges are also presented in the last chapter of this thesis.
\end{abstract}

Keywords: Zinc oxide ( $\mathrm{ZnO})$, hydrothermal growth, piezoelectricity, nanowires (NWs), nanogenerator (NG), energy harvesting, wireless data transmission. 


\section{Acknowledgments}

First of all and at this stage of accomplishment, first and foremost, I must acknowledge and thank The Almighty Allah who give me courage to complete this work and for blessing, protecting, and guiding me throughout this journey and all my life. I could never have achieved this without the faith I have in Allah.

I would like to express my deepest gratitude to Associate prof. Omer Nour. I am extremely fortunate to have such a great man as my advisor and mentor. I am delighted to gratefully thank him for his excellent supervision and excellent cooperation. The time, support, and guidance that he provided me throughout the duration of my Ph.D. study are immeasurable

I would like to express my sincere gratitude to my co-supervisor, Prof. Magnus Willander, I am delighted to gratefully thank him for his excellent supervision and excellent cooperation, and for his guidance, positive encouragements contribution with valuable points of view, suggestions and endless support through the duration of my Ph.D. study.

I would like to thank all of my co-authors for their positive contributions, excellent support and encouragements.

I am delighted to gratefully acknowledge Linkoping University- Department of Science and Technology (ITN) for the four-year fellowship/scholarship award and also for the continued generous support through the duration of my Ph.D. study. I would like to thank all the staff members of ITN for their help and support. Special thanks go to our research administrator Ann-Christin Norén for her kind help and support in my life and work. Also, I am deeply indebted to all the staff members of ITN and IFM Laboratories that I worked in. Special thanks to Lars G, Bengt, Anna and Putte for keeping the lab running.

I wish to express my sincere thanks to Adriana Serban and prof. Mohamed Sid-Ahmed for their support and encouragement during my studies and research work.

I am deeply indebted to my Sudan University of Science and Technology for providing financial support during my $\mathrm{PhD}$ study. Together with my colleagues at the Department of Physics, Faculty of Science, SUST, thank you all for your support.

I am also very grateful to the alumni and present members of Physical Electronic and Nanotechnology at Linköping University, for contributing to creating conductive environment for promoting fruitful cooperation within this group through valuable assistance and lots of fun.

Special thanks go to Prof. Per-Olof Holtz, the head of Agora Materiae research school for all the care, support and organization of seminars/ study visits with an enabling environment.

Finally, I would like to gratefully thank my parents, as well as all my sisters, brothers and friends for their love, steady support, and encouragement during all these years. Especial thanks to Lana, Samia and Tayseer for their love, care and encouragement.

Thank you all!

Eiman, Norrköping in November 2016. 


\section{List of publications included in the thesis}

\section{Paper I}

Handwriting enabled harvested piezoelectric power using $\mathrm{ZnO}$ nanowires/polymer composite on paper substrate.

E. Nour, M. Sandberg, M. Willander and O. Nur. Nano Energy 9 (2014) 221.

\section{Paper II}

Low-frequency self-powered footstep sensor based on $\mathrm{ZnO}$ nanowires on paper substrate.

E. S. Nour, A. Bondarevs, P. Huss, M. Sandberg, S. Gong, M. Willander and O. Nur. Nanoscale Research Letters 11 (2016) 156.

\section{Paper III}

Low frequency accelerator sensor based on piezoelectric $\mathrm{ZnO}$ nanorods grown by low temperature scalable process.

E. S. Nour, C. O. Chey, M. Willander and O. Nur. Physica Status Solidi 26 (2016) 095502 .

\section{Paper IV}

A flexible anisotropic self-powered piezoelectric direction sensor based on double sided $\mathrm{ZnO}$ nanowires configuration chemical.

E. S. Nour, C. O. Chey, M. Willander and O. Nur. Nanotechnology 26 (2015) 095502 .

\section{Paper V}

A flexible sandwich nanogenerator for harvesting piezoelectric potential from single crystalline zinc oxide nanowires.

E. S. Nour, A. Khan, O. Nur and M. Willander. Nanomaterials and Nanotechnology 4 (2014) 24.

\section{Paper VI}

Piezoelectric and opto-electrical properties of silver-doped $\mathrm{ZnO}$ nanorods synthesized by low temperature aqueous chemical method.

E. S. Nour, A. Echresh, X. Liu, E. Broitman, M. Willander and O. Nur. AIP Advances 5 (2015) 077163.

\section{My contribution to the articles included in this thesis:}

I was involved in the planning of all six papers. I performed the synthesis, and did all experiments except wireless node (in paper II) and XPS and nanoindentation (in paper VI). Finally I wrote the first manuscript version of the six papers, and participate in all of the discussion in order to make the final scope. 


\section{List of publications not included in this thesis}

\section{Paper VII:}

\section{Invited Paper}

Comparison between different metal oxide nanostructures and nanocomposites for sensing, energy generation and energy harvesting

M. Willander, H. Alnoor, S. Elhag, Z. H. Ibupoto, E. S. Nour and O. Nur. SPIE Proceedings 9749 (2016).

\section{Paper VIII:}

The effect of $\mathrm{ZnO}$ nanostructures morphology on the piezo-optoelectric output.

E. S. Nour, H. Alnoor, M. Willander and O. Nur. (Manuscript).

\section{Paper IX:}

Triboelectric based ZnO NWs/PVDF-TrFE on paper substrate.

R. E. Adam, E. S. Nour, M. Willander and O. Nur. (Manuscript). 


\section{List of abbreviations}

\section{Abbreviation}

NS

$\mathrm{ZnO}$

$\mathrm{GaN}$

CdS

$\mathrm{ZnS}$

VLS

CVD

ED

ACG

NW

NB

NR

NG

SEM

TEM

AFM

PVDF

PVDF-TrFE

PEDOT: PSS

PET

$\varepsilon$

CB

VB

$\mathrm{MgO}$

$\mathrm{CdO}$

DI - water

Ag

$\mathrm{Au}$

$\mathrm{Al}$

$\mathrm{Cr}$

HMTA

$\mathrm{KOH}$

XRD

JCPDS

XPS

UV-Vis

BE

I-V

$\mathrm{d}_{33}$

\section{Word or Phrase}

Nanostructure

Zinc oxide

Gallium nitride

Cadmium sulfide

Zinc sulfide

Vapor liquid solid

Chemical vapor deposition

Electrochemical deposition

Aqueous chemical growth

Nanowire

Nanobelt

Nanorod

Nanogenerator

Scanning electron microscope

Transmission electron microscope

Atomic force microscope

Polyvinylidene fluoride

Polyvinylidene fluoride trifluoroethylene

poly(3,4-ethylenedioxythiophene)

Polyethylene terephthalate

Strain

Conduction band

Valance band

Magnesium oxide

Cadmium oxide

Deionized water

Silver

Gold

Aluminum

Chromium

Hexamethylenetetramine

Potassium hydroxide

X-ray diffraction

Joint committee on powder diffraction standards

$\mathrm{X}$-ray photoelectron spectroscopy

Ultra violet visible

Binding energy

Current voltage

Piezoelectric effect 


\section{List of units}

Symbol
$\mathrm{eV}$
$\mathrm{meV}$
$\mathrm{nm}$
$\mu \mathrm{m}$
$\mathrm{PC} / \mathrm{N}$
$\mu \mathrm{N}$
$\mathrm{pW} / \mathrm{mm}^{2}$
$\mathrm{mbar}$
${ }^{\circ} \mathrm{C}$
$\mathrm{rpm}$
$\mathrm{mM}$
$\mathrm{KV}$
$\AA$
$\Omega$
$\mathrm{V}$
$\mathrm{mV}$
$\mathrm{mA}$
$\mu \mathrm{A}$
$\mathrm{mW} / \mathrm{mm}^{2}$
$\mathrm{MHz}$
$\mathrm{W}$
$\mathrm{mW} / \mathrm{mm}^{2}$
$\mu \mathrm{W}$
$\mathrm{Hz}$
$\mathrm{m} / \mathrm{s}^{2}$
$\mathrm{Vs} / \mathrm{m}$
$\mathrm{g}$
$\theta$
$\mathrm{Pa}$
$\mathrm{N}$

\section{Unit}

Electron volt

Mili electron volt

Nanometer

Micrometer

Pico coloumb per newton

Micro newton

Pico watt per squire milimeter

Millibar

Degree centigrade

Revolutions per minute

Millimole

Kilo volt

Angstrom

Ohm

Volt

Millivolt

Mili ampere

Micro ampere

Mili watt per squire milimeter

Megahertz

Watt

Mili watt per milimeter

Micro watt

Hertz

Meter per squire seconds

Volt squre seconds/ meter (Sensitivitiy)

Gram

Angel degree

Pascal

Newton 


\section{List of figures}

Figure 2-1: Non-central symmetry in $\mathrm{ZnO}$ wurtzite structure. This non-central symmetry is 9 causing the observed piezoelectric effect for $\mathrm{ZnO}$ [Adopted from 3].

Figure 2-2: Schematic diagram showing where the $\mathrm{ZnO} \mathrm{NR}$ is agitated by an external load 10 like mechanical energy applied (or vibration) through the flexible PEDOT:PSS substrate.

Figure 2-3: Graphical illustration of the nanoindentaion test for the (a) direct and (b) 11 converse piezoelectric effect.

Figure 2-4: Structure of the Polyvinylidene fluoride.

Figure 3-1: Schematic diagram of the synthesis of ZnO NSs using the hydrothermal method.

Figure 3-2: (a) Schematic diagram showing the structure of the general configuration used 22 for the piezoelectric NG. (b) A digital photograph of the final fabricated NG.

Figure 4-1: Bragg's Law reflection. The diffracted $x$-rays exhibit constructive interference when the distance between paths $\mathrm{ABC}$ and $\mathrm{A}^{\prime} \mathrm{B}^{\prime} \mathrm{C}^{\prime}$ differs by an integer no. of the wavelengths $(\lambda)$.

Figure 4-2: Graphical illustration of the nanoindentaion test for the (a) direct and (b) 26 converse piezoelectric effect.

Figure 5-1: (a) SEM image of the $\mathrm{ZnO}$ nanowires (NWs) grown on paper substrate. (b) Shows a schematic diagram displaying the structure of the general configuration used for the present piezoelectric NG. (c) Schematic diagram illustrating different possibilities of the $\mathrm{ZnO}$ NWs bending due to pressure exerted while handwriting is applied. The expected voltage polarity on the paper contact (top and bottom) is also shown.

Figure 5-2: $(\mathrm{a}, \mathrm{b})$ The output voltage/current achieved using $\mathrm{ZnO}$ NWs filtered powder as a function of time at low and high speed handwriting, respectively. (c) The maximum output power density as a function of the load resistance for a $\mathrm{NG}$ based on $\mathrm{ZnO} \mathrm{NWs}$ /PVDF polymer ink pasted and sandwiched between two pieces of paper with $\mathrm{ZnO} \mathrm{NWs}$ grown chemically on one side of each piece of paper is shown [5]. The inset is a digital photograph showing a light emitting diode operated by handwriting harvested power from the handwriting enabled paper NG.

Figure 5-3: (a) The performance of $\mathrm{ZnO} N W \mathrm{~N} / \mathrm{PVDF} \mathrm{NG}$ fabricated on paper substrate and on PEDOT:PSS plastic platforms for comparison. (b) The open circuit output voltage as a function of time of a NG fabricated by pure polymer ink sandwiched between two ZnO NWs grown on paper.

Figure 5-4: (a) Schematic diagram showing the NGs device. (b and c) The output voltage and current as a function of time, under repeated footsteps.

Figure 5-5: (a) Schematic diagram of the complete electronic circuit during measurements, (b) the average output voltage as a function of time under many footsteps when the amplifier is connected to one NG.

Figure 5-6: (a) Representative SEM image of the $\mathrm{ZnO}$ nanorods synthesized on PEDOT:PSS plastic substrate. (b) Schematic diagram showing the flexible NG. (c) Schematic diagram shows where the $\mathrm{ZnO} \mathrm{NR}$ is agitated by an external vibration/load mechanical energy applied through the flexible PEDOT:PSS substrate. 
Figure 5-7: (a) The output voltage versus the compressive stress at different low frequencies 36 $(5-41 \mathrm{~Hz})$. (b) The maximum output voltage as a function of acceleration. (c) The output voltage versus the compressive stress for mass weights of (10-1000 g). (d) Output voltage as function of the pressing and releasing during finger print pressure. The inserts is a digital photograph showing the corresponding finger pressure experiment.

Figure 5-8: (a) Schematic diagram showing a double sided NG. (b) The polarity of the output voltages under bending for case of the downward bending. (c) The measured output voltage for a period of millisecond obtained from the top side NWs (green) and bottom side (blue), the inserts show the corresponding measurement side. (d) The generated output voltage from both sides during compressing and releasing for a period of about $60 \mathrm{~s}$.

Figure 5-9: (a) Schematic diagram showing the bending angle measurement configuration.

(b-d) The maximum output voltage as a function of the bending angle (from $0^{\circ}$ to $90^{\circ}$ ) for the different connections as shown in the inserts of each curve.

Figure 5-10: The instantaneous output voltages of the NG based on (a) PEDOT:PSS, and (b) 40 silver coated plastic substrates

Figure 5-11: (a) ZnO NWs grown on $\mathrm{Ag}$ and Au substrates. (b) Shows the application of 40 external force to the surface of the NG configuration.

Figure 5-12: Measurement of the piezoelectric potential and the corresponding current by open circuit and short circuit measurements from the three configurations: (a-b) $\mathrm{Ag} / \mathrm{ZnO}$ NWs/Au, (c-d) Ag/ZnO NWs-ZnO NWs/Au, and (e-f) Ag/ZnO NWs-PVDF-ZnO NWs/Au.

Figure 5-13: (a) XRD patterns for all the $\mathrm{Zn}_{1-\mathrm{x}} \mathrm{Ag}_{\mathrm{x}} \mathrm{O}$ NRs grown on silicon substrate ( $\mathrm{x}$ value is as indicated). (b) The XRD patterns of the (002) diffraction peaks. (c) SEM image of all the silver doped $\mathrm{Zn}_{1-\mathrm{x}} \mathrm{Ag}_{\mathrm{x}} \mathrm{O}$ NRs grown on silicon substrate ( $\mathrm{x}$ value is as indicated).

Figure 5-14: (a) XPS spectrum of $\mathrm{Ag} 3 \mathrm{~d}$ peaks for the $\mathrm{Zn}_{1-\mathrm{x}} \mathrm{Ag}_{\mathrm{x}} \mathrm{O}$ NRs grown on silicon substrate ( $\mathrm{x}$ value is as indicated). All XPS peaks were normalized. The dashed line indicates the change of the Ag peak position with doping. (b) Plot of $(\alpha h v)^{2}$ versus $h v$ of the $\mathrm{ZnO}$ (black), $\mathrm{Zn}_{0.97} \mathrm{Ag}_{0.03} \mathrm{O}$ (red), $\mathrm{Zn}_{0.94} \mathrm{Ag}_{0.06} \mathrm{O}$ (orange) and $\mathrm{Zn}_{0.91} \mathrm{Ag}_{0.09} \mathrm{O}$ NRs (blue).

Figure 5-15: (a) Graphical representation of the nanoindentaion test for the direct piezoelectric effect. (b) Generated piezoelectric potential as a function of the applied load. (c) Graphical representation of the nanoindentaion test for the converse piezoelectric effect. (d) Piezoelectric coefficient as a function of the doping concentration. 


\section{Table of contents}

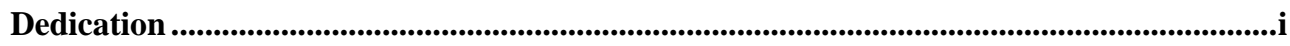

Abstract...............................................................................................................................ii

Achnowledgements ................................................................................................................................. iii

List of publication included in this thesis ...................................................................................iv

List of publication not included in this thesis...............................................................................

List of abberviations .............................................................................................................vi

List of units .....................................................................................................................................vii

List of figures........................................................................................................................... viii

Chapter one: Introduction ..........................................................................................................2

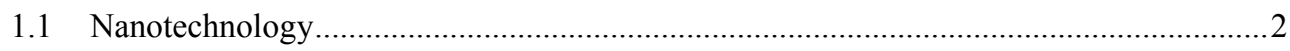

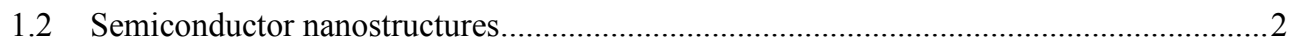

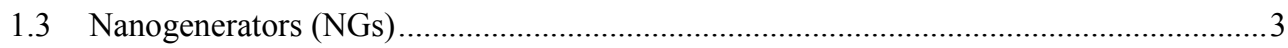

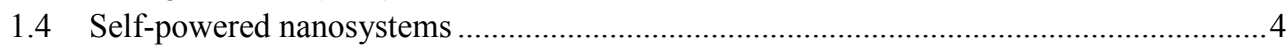

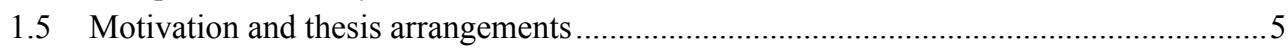

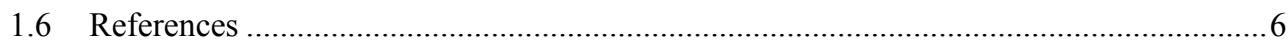

Chapter two: Materials and properties ..................................................................................8

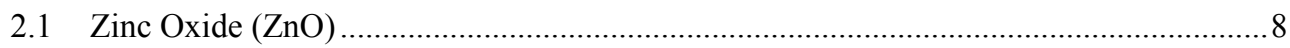

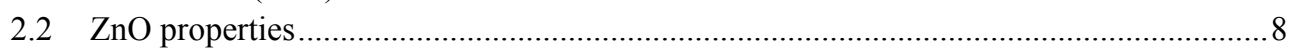

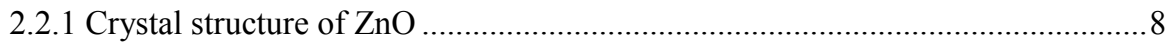

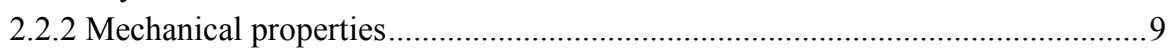

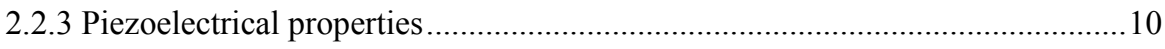

2.2.3.1 Direct and indirect piezoelectric effects .............................................11

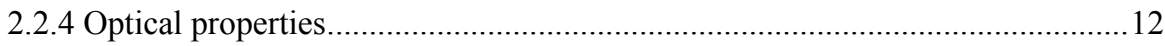

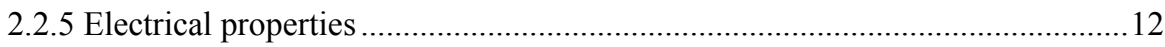

2.3 Harvesting mecanihcal energy from $\mathrm{ZnO}$ nanostructures ..............................................13

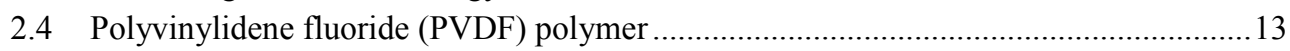

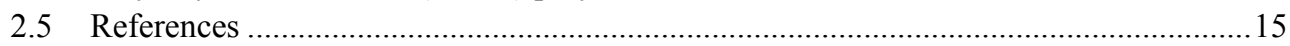

Chapter three: Synthesis of nanostructured materials and device processing ...................18

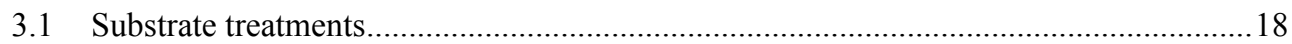

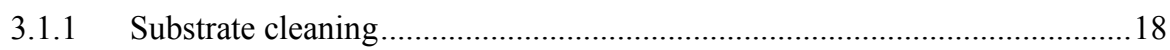

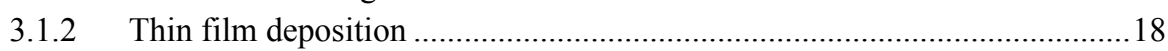

3.1.3 Preperation of $\mathrm{ZnO}$ seed solution ................................................................ 19

3.1.4 Deposition of seed solution ....................................................................19

3.1.5 Post seed layer deposition process ............................................................19

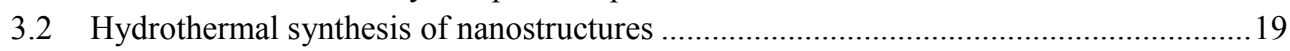

3.2.1 Synthesis of the $\mathrm{ZnO}$ nanowires/nanorods (NWs/NRs) ...............................20

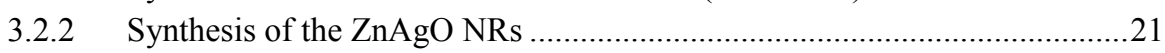

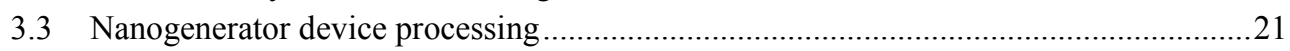

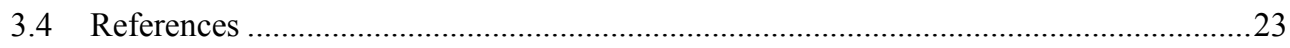

Chapter four: Characterization tools and techniques..............................................................24 
4.1 Structural and morphology characterization studies ..................................................24

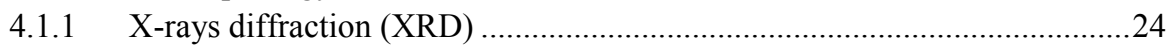

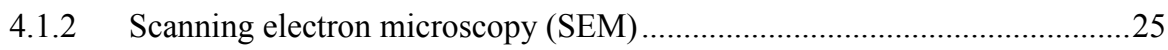

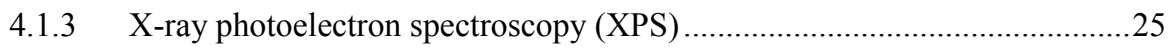

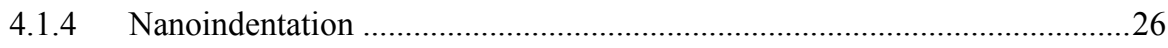

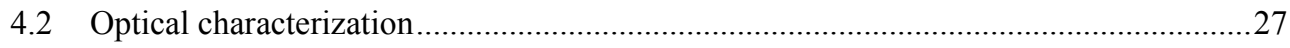

4.2.1 Ultraviolet-visible spectroscopy (UV-vis) ...............................................2

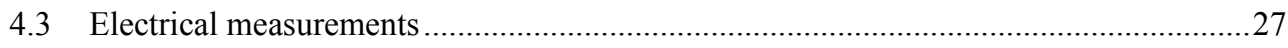

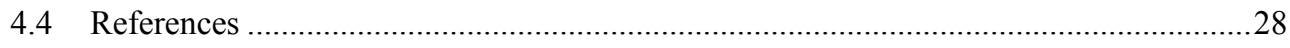

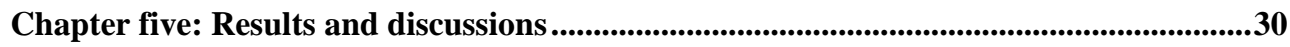

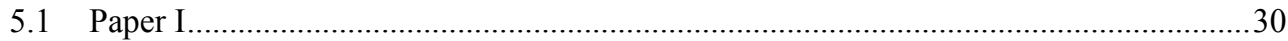

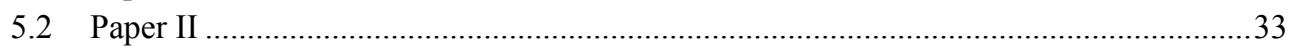

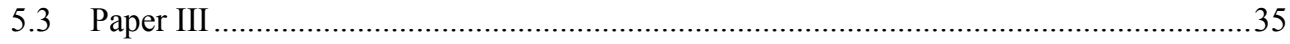

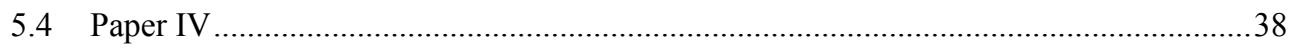

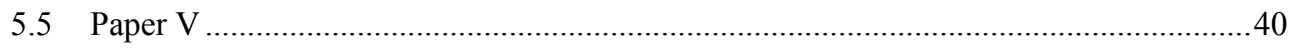

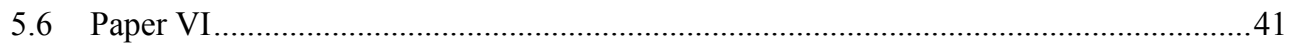

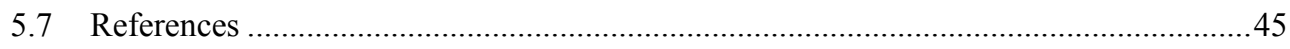

Chapter six: Summary and future prospective..................................................................................46

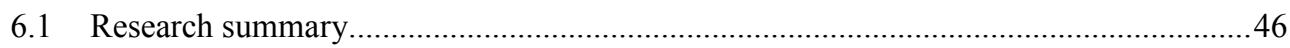

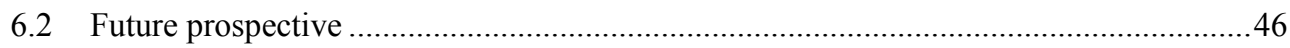

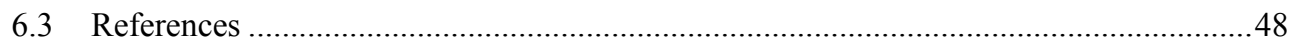






\section{Chapter one: Introduction}

\subsection{Nanotechnology}

In a talk presented at California Institute of Technology, in December 1959, by the physicist Richard Feynman entitled "there is plenty of room at the bottom", the idea about nanotechnology was introduced. In that talk, Feynman depicted a method that assist a researcher to tune and adjusting specific atoms and molecules [1]. More than a decade after that talk, Professor Norio Taniguchi mentioned the term nanotechnology. In 1981, the development of the scanning tunneling microscope helped in "seeing" individual atoms, and that was the start of modern nanotechnology. The development of the scanning electron microscope enabled the ability to see and to manipulate specific atoms and molecules. Nanotechnology is the study and application of extremely small objects, and is used for all fields of science, such as physics, biology, chemistry, materials science, medicine, and engineering [2]. Nowadays, researchers are utilizing the advantageous properties of nanostructures over their bulk counter partner, in many applications.

\subsection{Semiconductor nanostructures}

Semiconductor nanostructures (NSs) are unique as functional building assembles in a wide variety of nanoscale devices. Semiconductor NS materials such as $\mathrm{ZnO}, \mathrm{GaN}, \mathrm{CdS}$, and possibly $\mathrm{ZnS}$ can play a significant function to cooperate with objects in connection to energy issues. Therefore, semiconducting, piezoelectric and pyroelectric properties of different semiconducting NSs are very important. Such NSs, has practically research areas of optoelectronics, sensors, and actuators [3-5]. In general, some NSs possess a high surface area to volume ratio, and in addition to low toxicity, being environment-friendly, with excellent chemical stability and can be biocompatible in some metal oxide NSs. Since the last two decades, research on metal oxides NSs and especially ZnO has been successful due to its unique physical and chemical properties. There are two possible routes to have a NS, these are either by using the "top down" or the "bottom up" approach. The top down approach is by using lithographic methods and although it is the best for some special applications, like e.g. photonic crystals, it is quite costly and time consuming. On the other hand the bottom up approach, which is more popular than the top-down approach due to the fact that the former is considered better in creating NSs having lower defects, also homogenous in their chemical composition, and crystal quality [6,7]. In addition to the fact that the cost is much lower when using the bottom-up approach.

The bottom up approach is further divided into either being physical or chemical. The physical routes are usually high temperature (few $100 \mathrm{~s}{ }^{\circ} \mathrm{C}$ ). While the chemical routes are usually low temperature $\left(<100^{\circ} \mathrm{C}\right)$. The latter is attractive due to the possibility of using soft substrates like paper, plastic, textile, etc.. Example of typical physical methods used are the vapor-liquid-solid (VLS) technique [8] and chemical vapor deposition (CVD) [9, 10]. While typical chemical methods used are the electrochemical deposition (ED) [11], and the hydrothermal methods $[12,13]$. Recently, the aqueous chemical growth (ACG) methods used 
to synthesize metal oxide NSs have become very popular among researchers $[14,15]$. This is due to the low temperature $\left(<100^{\circ} \mathrm{C}\right)$, being cheap, at the same time environment-friendly and simplicity of the method. In addition to that, the different properties of any material can in principle be tuned by varying different growth parameters, like e.g. the preparation routines and recipe, temperature etc.. [16]. Furthermore, $\mathrm{ZnO}$ has distinctive and attractive morphologies in zero dimensional configurations such as nanoparticles and quantum dots, or one dimensional configurations, such as nanowires (NWs), nanorods (NRs), or two dimensional configurations like e.g. nanosheets and nanowalls, and three dimensional configurations such as nanotubes, nano leaves, nanoflowers, nano tetrapods etc.. [17-20]. An advantageous reason making them useful to fabricate and developing nano devices for sensing, personal electronics, optoelectronic, biomedical devices and a battery-less systems for future applications [21, 22].

\subsection{Nanogenerators (NGs)}

A nanogenerator $(\mathrm{NG})$ is a component converting energy into a useful electrical energy based on the energy conversion by nanostructured material. The three distinctive methodologies of a NG are piezoelectric, triboelectric and pyroelectric NG.

A piezoelectric $\mathrm{NG}$, is a device that employs active materials that generates charges when it is mechanically stressed, converting mechanical energy into electricity. The name NG, however, might mean any type of device that is based on a NS and converts any type of energy from the surroundings, like e.g. airflow, wind, ambient noise, vibration and human body movements, it is specifically used to define piezoelectric based device utilizing kinetic energy when it was demonstrated for the first time in 2006 [23]. It is important to note that the development of NG is at an early stage, the demonstration has been considered as a breakthrough because of the potential as an energy harvester promising technology. The development of NGs is expected to also lead to possible facile integration with other energy harvester converting different types of energy e.g. integration with solar energy convertors. Such energy harvesting system can be used to power mobile electronic devices with reduced concerns for the energy source [24]. However, the concept of the NG is associated with the coupling of the piezoelectric and the semiconducting properties. In a case of a stress is applied by an external force, the $\mathrm{ZnO} \mathrm{NWs}$ grown parallel to the c-axis are under uniaxial compression. A piezoelectric potential will exist with different polarity occurs, respectively, at the top and bottom sides of the ZnO NWs. Transient current then flows from the top to the bottom of the NW, then through the external circuit [25]. This is then detected as an electric pulse. By eliminating the external force, the piezoelectric potential in the NWs will vanish. Therefore, an AC current is harvested [25].

In triboelectric NGs, the electrostatic charges appearing on the surfaces of two different materials when they are in physical contact, is utilized. Under applied force, the charges and dis charges appear in triboelectric as a result of contact and separation of the two materials. This lead to passing electrons between the two electrodes of the material. The triboelectric phenomenon is the source of the lightning we see on cloudy days due to the 
friction and movement of different clouds on top of each other. The first report of the modern triboelectric NG was published by Z. L. Wang et. al. in 2012 [26].

A pyroelectric NG converts the thermal energy into electrical energy by the pyroelectric effect. Typically, a pyroelectric NG largely relies on seebeck impact that using temperature variation at the end of the device for driving the diffusion of charge carriers [27].

\subsection{Self-powered nano-systems}

Self-powering with long term operation, and practical characterizations is important part of a wide range wireless components like e.g. space monitoring. And is also used to control and diagnosis for different sectors, like e.g. military, commercial, industrial, space research, in addition to many different biomedical applications. Relatively long operational life-time, though when the energy amount is low, it's not easy to operate small devices (i.e. nano/ micro devices). So, finding sustainable energy sources, such as harvesting ambient energy will assist finding solutions for the long lasting functional shortage.

Nanodevices developed to demonstrate wireless nanosystems are attracting more and more attention for both the industry as well as for the academic communities. Moreover, these nanodevices are of critical importance for sensing, medical science, etc.. It is potentially top required for wireless and execute biomedical devices with no storage employments. This exactly explains the so called self-powered nanosystems [28, 29]. Self powered systems are of potential for powering small components in personal electronics (e.g. mobile phone) [2729]. This makes them possible to be used for energy harvesting, from mechanical disturbances and our living environment. It is not effective if for example, sensor networks have to be powered by batteries because, in addition to the high replacement and service cost, the possible health hazards from waste is also can be found [24]. Therefore, innovative powering sources are desperately required for maintenance-free, and sustainable operation for electronic devices. This technology is quite innovative and can be used for nano/ microelectromechanical (NMEMS) systems, home security applications, a variety of sensing systems etc.. [24].

Owing to the increased demand for alternative self-powering technology, photovoltaic, low-powered CMOS and hybrid self-powered, attracted great attention in recent years. Furthermore, most of the research work published on NGs rely on high frequencies external forces. Subsequently, new innovative solutions that can lead to harvesting sustainable energy from the surroundings offers an environmental friendly alternative are required. Nanomaterials employment for energy harvesting is a rising filed, with potential for providing sustainable power sources to some nanosystems. It can be used possibly to avoid batteries, this will lead to develop self-powered active sensors which largely facilitate the wide range of applications for wireless sensor networks [24]. 


\subsection{Motivation and thesis arrangement}

The aim of this study is to investigate NGs based devices and use them for energy harvesting applications at relatively low frequencies e.g. $<100 \mathrm{~Hz}$. According to literature review, piezoelectric NG has been the most attractive and promising technology for providing power to various low power electronics. This is in addition to the motivation to fabricate a NG capable to harvest energy from human body activities and especially body movements $(<100$ $\mathrm{Hz}$ ). This is a very prospective field.

This thesis is arranged as follows: starting from the basic semiconductor materials i.e. $\mathrm{ZnO}$ and its properties in order to develop devices. Followed by description of synthesizes and growth techniques of the NSs based on the low temperature hydrothermal chemical routine. A brief discussion on processing these NSs to function as NG devices is also presented. Various techniques that have been used to characterize the structures, morphologies and properties of the NS materials. X-ray diffraction and scan electron microscope are typical examples of those techniques. All the techniques used are then described in a separate chapter. After that, we discussed the results achieved during the research efforts within this thesis. However, different NGs configuration devices have been fabricated and used to serve as handwriting sensor, foot-step triggered sensor for wireless network systems, accelerator sensor and anisotropic direction sensor. Further, these devices showed stability in sensing and it can be used in many applications such as personal electronics, surveillances, security and even automobile, etc.. Finally a brief summary into future prospective is discussed. 


\subsection{References}

[1] S. J. Updike, J. P. Hicks, Nat., 214 (1967) 986.

[2] S. Su, W. Wu, J. Gao, J. Lu, C. Fan, J. Mater. Chem., 22 (2012) 18101.

[3] N. Chopra, V.G. Gavalas, L.G. Bachas, B.J. Hinds, L.G. Bachas, Anal. Lett., 40 (2007) 2067.

[4] K. Kerman, M. Saito, S. Yamamura, Y. Takamura, E. Tamiya, Trends Anal. Chem., 27 (2008) 585.

[5] D. Chow, M. Johannes, W. Lee, R. Clark, S. Zauscher, A. Chilkoti, Mat. Tod., 8 (2005) 30.

[6] Z. M. Wang, Springer Science + Business Media, Springer, (2008).

[7] G. Z. Cao, Y. Wang, World Scientific Publishing Co. Pte. Ltd, (2010).

[8] M. H. Huang, S. Mao, H. Feick, H. Yan, Y. Wu, H. Kind, E. Weber, R. Russo, P. Yang, Sci., 292 (2001)1897.

[9] J. J. Wu, S. C. Liu, Adv. Mat., 14 (2002) 215.

[10] J. J. Wu, S. C. Liu, J. Phys. Chem. B, 106 (2002) 9546.

[11] R. Liu, A.A. Vertegel, E.W. Bohannan, T.A. Sorenson, J.A. Switzer, Chem. Mat., 13 (2001) 508.

[12] L. Vayssieres, Adv. Mat., 15 (2003) 464.

[13] M. Guoa, P. Diao, S. Cai, J. Sol. Sta. Chem., 178 (2005) 1864.

[14] G. Amin, M. H. Asif, A. Zainelabdin, S. Zaman, O. Nur, M. Willander, J. of Nanomat., 2011 (2011) 269692.

[15] A. Zainelabdin, S. Zaman, G. Amin, O. Nur, M. Willander, Cryst. Grow. Desi., 10 (2010) 3250.

[16] E. S. Nour, A. Echresh, X. Liu, E. Broitman, M. Willander, O. Nur, AIP Adv., 5 (2015) 077163.

[17] M. S. Mo, J. C. Yu, L. Z. Zhang, S. A. Li, Adv. Mat., 17 (2005) 756.

[18] Z. W. Pan, Z. R. Dai, Z. L. Wang. Sci., 291 (2001) 1947.

[19] C. Periasamy, P. Chakrabarti, JAP, 109 (2011) 054306.

[20] A. Khan, M. A. Abbasi, J. Wissting, O. Nur, M. Willander, Phys. St. So. (RRL), 7 (2013) 980.

[21] S. Xu, Z. L. Wang, Nano Res., 4 (2011) 1013.

[22] S. Kishwar, M.H. Asif, O. Nur, M. Willander, P.O. Larsson, Nanoscale Res. Lett, 5 (2010) 1669.

[23] Z. L. Wang, J. H. Song, Sci., 312 (2006) 242.

[24] Z. L. Wang, Adv. Mat., 24 (2011) 280.

[25] S. Lee, J. Hong, C. Xu, M. Lee, D. Kim, L. Lin, W. Hwang, Z. L. Wang, Ad. Ma., 24 (2012) 4398.

[26] F-R. Fan, Z.-Q. Tian, Z. L. Wang, Nano Ener., 1 (2012) 328.

[27] Y. F. Hu, Y: Zhang, C. Xu, L. Lin, R. L. Snyder, Z. L. Wang, Nano Lett., 11 (2011) 2572. 
[28] Z. L. Wang, Sci. Amer., 298 (2008) 82.

[29] Z. L. Wang, Adv. Fun. Mat., 18 (2008) 3553. 


\section{Chapter two: Materials and properties}

This chapter aims to describe and narrate the properties of the materials used to develop devices. With these properties, different applications can be obtained, such as sensing and energy harvesting, etc..

\subsection{Zinc Oxide $(\mathrm{ZnO})$}

Zinc oxide $(\mathrm{ZnO})$ is naturally n-type semiconductor, and has attracted much attention by the researcher in the past few years due to its unique and prosperous properties. Although the first published paper on $\mathrm{ZnO}$ dates back to the $30 \mathrm{~s}$, the research on $\mathrm{ZnO}$ has been fluctuating due to the difficulty in obtaining stable p-type doping [1]. Nevertheless, the nanostructure (NS) form of $\mathrm{ZnO}$ provides the possibility of integrating $\mathrm{ZnO}$ with other p-type materials. The possibility of integrating $\mathrm{ZnO}$ NSs with other materials is one of the reasons of the intense interest in $\mathrm{ZnO}$ research during the past years. $\mathrm{ZnO}$ is a II-VI semiconductor that possesses a direct band gap of $3.34 \mathrm{eV}$ and has relatively large exciton binding energy of 60 $\mathrm{meV}$ both at room temperature. Moreover, $\mathrm{ZnO}$ has a high stable non-centro-symmetric hexagonal wurtzite structure leading to a relatively large piezoelectric coefficient, high modulus of elasticity and high piezoelectric tensor. In fact, $\mathrm{ZnO}$ has for some years attracted the research community's attention due to these excellent properties, combined with the fact that in the NS form, $\mathrm{ZnO}$ has many advantages that can be utilized. $\mathrm{ZnO}$ possesses the richest family of different morphologies, possible to obtain using a variety of physical and chemical synthesis techniques [2]. Due to this variety of applications, $\mathrm{ZnO}$ is reversed as a prospective material, especially in the NSs form, with the possibility to utilize $\mathrm{ZnO}$ properties in many applications like e.g. sensing, energy harvesting, and photonics. This in addition to the property of biocompatibility, inherent piezoelectricity, cheap, synthesis and fabrication possibilities which all make it useful for energy harvesting applications [1, 2].

\section{2 $\mathrm{ZnO}$ properties}

\subsubsection{Crystal structure of $\mathrm{ZnO}$}

$\mathrm{ZnO}$ has a wurtzite structure with a hexagonal unit cell that belongs to the space group C6mc. It has a lattice parameters $\mathrm{a}=0.3296$, and $\mathrm{c}=0.52065 \mathrm{~nm}$. The oxygen anions and zinc cations form a tetrahedral unit, and the entire structure lacks a central symmetry [3]. The crystal of $\mathrm{ZnO}$ can be viewed as alternating set of planes of tetrahedral coordination of $\mathrm{O}^{2-}$ and $\mathrm{Zn}^{2+}$ ions placed on top of each other along the c-axis as schematically shown in Figure $(2-1)$.

Although the nature of $\mathrm{ZnO}$, its cryptography can be describe by the distributions of cations and anions with cretin arrangements. Therefore, with the cations or anions, some surfaces can end up with a net negative or positive charge. Then a positively or negatively charged surfaces known as polar surfaces do exist. The basal plane is an example of polar 
surface. A dipole moment and then a polarization along the c-axis can be produced due to oppositely charged ions [positively charged $\mathrm{Zn}^{2+}$ (0001) and negatively charged $\mathrm{O}^{2-}$ $\left(0001^{-}\right)$polar surfaces]. Generally, in order to have a settled structure polar surfaces have faces that show huge surface reconstructions $[4,5]$. This process repeated many times and lead to fast growth in the \pm (0001). Although the property of atomically flat, stable $\mathrm{ZnO} \pm$ (0001) polar surfaces; more investigations are under studying [6-9]. Beside the polar

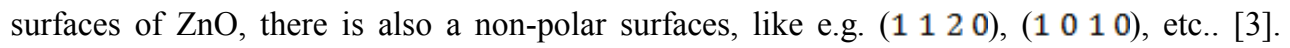
Because of the exposing the non-polar surfaces in the solution at the growth stage, this exactly the base of one dimension growth. This is a property that can be utilized to synthesize different novel $\mathrm{ZnO}$ NSs by controlling the growth parameters and conditions [3].

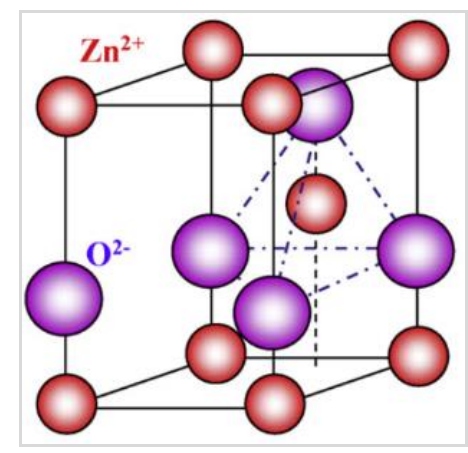

Figure 2-1: Non-central symmetry in $\mathrm{ZnO}$ wurtzite structure. This non-central symmetry is causing the observed piezoelectric effect for $\mathrm{ZnO}$ [Adopted from 3].

\subsubsection{Mechanical properties}

The stiffness, hardness, piezoelectric constants, Young's modulus, and yield strength are all among the useful mechanical properties of materials. Furthermore, the strain is the property that describes the deformation of materials when experiencing external mechanical force. It is obvious that investigating $\mathrm{ZnO} \mathrm{NSs}$ mechanical behavior is important to successfully incorporate these nanoscale materials as electromechanical components [10]. To design and fabricate functional electromechanical components it is important to have a deep knowledge about the mechanical properties. Mechanical characterization of single NW is challenging, basically due to the difficulties in performing mechanical tests on a single NW [11]. Due to large demand of fabricating piezoelectric nanogenerators ( $\mathrm{NGs}$ ) based on $\mathrm{ZnO}$, then it is very important to study and understand their mechanical behavior. Hence, the mechanical characterization of NSs plays a significant role for achieving efficient and reliable piezoelectric devices and sensors.

Flexure and nano stressing stage in scanning electron microscope, transmission electron microscope, atomic force microscope measurements and nanoindentation technique are all useful analytical tools to study the mechanical properties of materials [12-18]. The latter, namely, the nanoindentation and due to its high spatial resolution and sensitive forcesensing is commonly used $[11,19]$. A piezoelectric transducer-based technique is another 
very popular methodology for mechanical and electromechanical characterization. The popularity of this technique is due to the high displacement resolution for sensing.

\subsubsection{Piezoelectric properties}

Jacques and Pierre Curie observed the piezoelectric effect in 1888. The piezoelectric effect is the strength of some materials to create an electric potential in reaction to applied mechanical stress. The applied stress changes the polarization density within the material's volume leading to the observed potential. As a requirement, only materials with non-centrosymmetric crystal structure can exhibit piezoelectric effect. Some of the commonly used/known piezoelectric material is $\mathrm{ZnO}$, and polyvinylidenefluoride (PVDF). Both materials were used in the research of this thesis.

When mechanical stress is applied to $\mathrm{ZnO}$, an effective accumulation of charges is shown; a reason makes $\mathrm{ZnO}$ promising piezoelectric material. Due to coupling between semiconducting and piezoelectric properties, $\mathrm{ZnO}$ is considered as prospective in energy harvesting applications. The spontaneous polarization along the c-axis leading to dipole moment is created by the opposite charges which are produced by the polar surfaces [20-31].

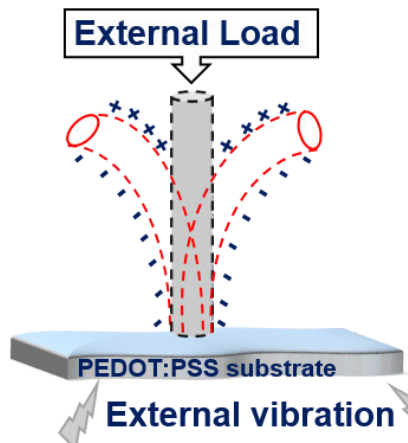

Figure 2-2: Schematic diagram showing where the $\mathrm{ZnO} \mathrm{NR}$ is agitated by an external load like mechanical energy applied (or vibration) through the flexible PEDOT:PSS substrate.

Generally, the deformation of $\mathrm{ZnO} \mathrm{NR}$ grown vertically along the c-axis, results in a strain distribution in the NR. Due to that strain, an electric field will be induced by the piezoelectric effect. The displacement of the $\mathrm{Zn}^{2+}$ cations when considering the $\mathrm{O}^{2-}$ anions will produce a potential. Then a potential distributions through NRs with a positive value in the stretched side and negative value in the compressive side will be observed [32- 33].

To evaluate the piezoelectric properties of any material attached to the substrate, It is essential to investigate about the piezoelectric coefficient $\left(\mathrm{d}_{33}\right)$ of the substrate material. It has been noted that the value of the piezoelectric coefficient $\left(\mathrm{d}_{33}\right)$ for $\mathrm{ZnO}$ is about 12.4 $\mathrm{pC} / \mathrm{N}$ for the bulk [32], and between 8-12 pC/N for thin films [32]. Such piezoelectric property and other properties (e.g. Young's modulus, elasticity, etc.) further can be 
determined by one of two possible methods. The first method is known as direct piezoelectric effect, while the second is known as indirect (converse) piezoelectric effect.

\subsubsection{Direct and indirect piezoelectric effect}

The piezoelectric effect can either be direct or indirect (converse). In the direct effect the external applied mechanical stress/ force will create an electric charge. While in direct piezoelectric effect, a mechanical strain/ force will be produced by the electric field. Under mechanical deformation for devices based on $\mathrm{ZnO}$ NSs, a piezoelectricity will be produced, this is an exact illustration of the direct piezoelectric effect [19]. In the direct piezoelectric effect, a strain appears inside the metal as a result of an external applied force. Therefore a potential distribution on the material surfaces is produced by the polarization, as shown in Figure 2-3 (a) [19]. In our work, the direct piezoelectric analysis was performed by applying a load of 0 to $160 \mu \mathrm{N}$ on the grown ZnO NRs by indenter tip [19]. These charges of the material generate a piezoelectric potential under any mechanical deformation caused by any external force.

(a)

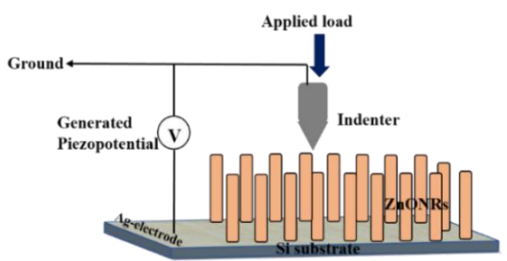

(b)

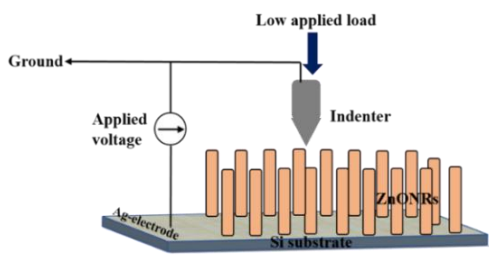

Figure 2-3: Graphical illustration of the nanoindentaion test for the (a) direct and (b) converse piezoelectric effect.

When a material exhibit mechanical compression or strain due to applied electric field in the direction of the applied electric field (as shown in Figure 2-3 (b)), it is called inverse piezoelectric effect, in which electrical energy is converted to mechanical energy. In our work, the converse piezoelectric effect was analyzed by applying a potential of 0 to $-40 \mathrm{~V}$ and the piezoelectric coefficient was calculated using equations (2-1) and (2-2).

As for the NRs, this coefficient $\left(d_{33}\right)$ is associated with the variation of the longitudinal elongation $(\Delta \mathrm{l})$ where the NRs respond to the variation of the applied voltage $(\Delta \mathrm{V})[17,20]$ :

$$
\mathrm{d}_{33}=\Delta \mathrm{L} / \Delta \mathrm{V}
$$

The converse piezoelectric effect $\left(d_{33}^{\text {eff }}\right)$ has a technological importance for the fabrication of our NG devices, since it's connected to the "real" piezoelectric coefficient $d_{33}$ of the bulk material as described in the equation below $[17,19]$ : 


$$
\mathrm{d}_{33}=\mathrm{d}_{33}^{\mathrm{eff}}\left(\mathrm{S}_{11}+\mathrm{S}_{12}\right) /\left(\mathrm{S}_{11}+\mathrm{S}_{12}+\mathrm{S}_{13}\right) \quad(2-2)
$$

where $\mathrm{S}_{11}, \mathrm{~S}_{12}$, and $\mathrm{S}_{13}$ are the mechanical compliances of the piezoelectric NRs.

\subsubsection{Optical properties}

The study of $\mathrm{ZnO}$ optical properties is very promising in nanotechnology research area. Because it is connected to the extrinsic and intrinsic atoms. The optical emission related to intrinsic property is due to recombinations between electrons in the conduction band (CB) and holes in the valence band (VB), i.e. excitons. In addition to contribution from deep level defects induced optical emission. On the other hand, extrinsic optical properties are caused by external foreign atoms introduced in the crystal. Due to their presence, an extra mid-gap states between the CB and VB are introduced, leading to extra recombination paths [34].

The intrinsic and the extrinsic defects in any crystal structure can play an important role on its optical properties. By controlling the density, quantity, and type of these point defects one can alter and modify the optical emission/absorption of the material [19, 35]. Such point defects usually appear either during synthesis or post synthesis processing steps. Vacancies are an example of intrinsic defect and it describe the absence of an anion or cation from the crystal. While $\mathrm{Cu}$ as a foreign impurity in $\mathrm{ZnO}$ atom is a typical example of a commonly observed extrinsic point defect.

Optical properties of $\mathrm{ZnO}$ has been on focus of intensive research for a long time. The relatively wide direct band gap and relatively large excitons binding energy of $\mathrm{ZnO}$ make it a material with potential for UV device development [36]. Nevertheless, the development of $\mathrm{ZnO}$ for device applications has been fluctuating for a long time. This was due to the difficulty in producing stable p-type. The recent development in synthesis and demonstration of a rich family of $\mathrm{ZnO}$ NSs have boosted the research because NSs possess a "small footprint" and hence can be synthesized and combined with other p-type materials. As shown in this thesis, $\mathrm{ZnO}$ functional nano-crystals can be even synthesized on amorphous substrates like glass, plastic paper etc.. Wide bandgap semiconductors usually possess higher density of free carrier trapping centers; thus allowing for more efficient radiative recombination processes. In order to form stable electron-hole pair at room temperature, the exciton value of binding energy should be higher than the thermal energy at room temperature. This is why $\mathrm{ZnO}$ has been known as a good luminescent material [37].

\subsubsection{Electrical properties}

As mentioned above, $\mathrm{ZnO}$ is potentially used in different electronic and optoelectronic applications. Possessing relatively high breakdown voltage, in addition to electrical operation with low noise and at high temperature are all related to the wide band gap in semiconductors. If $\mathrm{ZnO}$ is alloyed with other metal oxides like e.g. magnesium oxide or cadmium oxide, then its bandgap can be tuned between 3 to $4 \mathrm{eV}$ [34]. 
The strength of the electric field in $\mathrm{ZnO}$ will affect the transport properties $[34,38]$. In the case of applying a relatively low electric field, the electron energy can be lower than the thermal electron energy. That means, the electric field will not alter the electron distribution $[34,38]$. Hence the electron mobility will be the same, which means that the scattering rate will also be unaffected and Ohm's law prevail $[34,39]$. As the applied electric filed is higher than the thermal energy, the electron distribution function will deviates from its equilibrium since the electron energy is higher than the thermal energy [34, 39]. As no energy is dissipated to the lattice, the drift velocity of electrons can be relatively high and this implies that the material can be suitable to use for high frequency applications [34, 39]. Although a diversity of research results about the electrical properties, it's important to aware their potential in electronics applications [38, 40]. Since intrinsic $\mathrm{ZnO}$ is n-type, the origin of its conductivity is claimed to be related to $\mathrm{O}$ vacancies and $\mathrm{Zn}$ interstitials [41]. Nevertheless, there is still an ongoing debate on the origin and effect of point defects in $\mathrm{ZnO}$ [34].

\subsection{Harvesting mechanical energy from $\mathrm{ZnO}$ nanostructures}

Harvesting energy has attracted increasing attention since the past decade. This increased interest is due to the potential applications in developing self-powered systems based on NSs. The ambient mechanical energy is one of the sources that are abundant and hence different energy harvesting different components have been reported [43]. NGs using piezoelectric NWs have been developed as a key technology for converting mechanical energy into electricity. In 2006 Wang et al. introduced the first ZnO NG based on NWs using atomic force microscopy (AFM) and nanoindentation technique, the harvested piezoelectric potential produced was around $6.5 \mathrm{mV}$ with an output power density of $10 \mathrm{pW} / \mathrm{mm}^{2}$ [43]. Then in 2007 Xudong et al. reported a piezoelectric NG based on vertically aligned ZnO NWs arrays which relies on zigzag top electrode [44]. This act like an array of AFM tips that force the NWs to bend in response to external mechanical agitation caused by ultra-sonic wave [43].

Since then various NGs for ultrasonic, vibration, air pressure and body movement energy harvesting have been developed [43, 44]. However, it is important to investigate sustainable technologies to harvest different mechanical movements (e.g. related to human activity) under low frequency. Most of the developed NGs based on flexible substrates have shown enhancement in the amount of output power generated under mechanical deformation and can have many applications at low frequency [44- 46].

\subsection{Polyvinylidene fluoride (PVDF) Polymer}

Polyvinylidene fluoride (PVDF) and PVDF copolymers have attracted many researchers due to the combined piezoelectric, pyroelectric, and ferroelectric properties and hence their suitability for a wide range of applications [48]. PVDF is made-up of a semi-crystalline long chain polymer, that forms as repeated unit - CF2 - $\mathrm{CH} 2$ - (see Figure 2-4) [47, 48]. The inherent polar property of PVDF, is due to the different polarity of hydrogen (positive charge) and fluoride (negative charge) compared to carbon. It is important to note that the PVDF in its random orientation will have a zero polar moment [47]. 


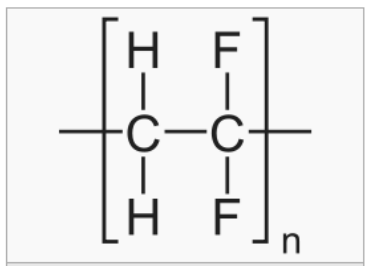

Figure 2-4: Structure of the Polyvinylidene fluoride.

A permanent dipole moment polarization of the PVDF can be achieved by stretching. As a result of this stretching, alignment of molecular chain is observed [47]. This alignment with the poling, and permanent dipole moment, are all confirms the piezoelectric behavior of the PVDF. In addition to the preferable piezoelectric property of the PVDF family, they are having light weight, are considered as good compliant class of material which shows considerable dielectric strength, high sensitivity to mechanical loads in diverse chemical environments. These features make the PVDF family of co-polymers potentially used in different applications such as sensors and transducers [47].

Furthermore, the combination of the PVDF with the copolymer trifluoroethylene ( $\mathrm{TrFE}$ ) is the most promising one in terms of electromechanical induced strain, which leads to large strain and high room temperature dielectric constant [49].

The attractive electromechanical properties of the PVDF co-polymers have motivated us to combine it with $\mathrm{ZnO}$ NSs. We utilized the dipole orientation property in the crystal phase of the PVDF to enhance the harvested output from our ZnO NSs based NGs. They are also compatible with the wet fabrication processes we have in our laboratory at ITN, Linköping University. Under an externally applied mechanical deformation, a sandwiched PVDF can be poled in all directions, and hence enhance the amount of the harvested output [50]. According to theoretical calculations, the output voltage from a NW is linearly proportional to the magnitude of the deformation caused by the external applied force or pressure [51]. Hence for maximizing the harvested mechanical energy an efficient transfer of the applied pressure would be preferable. While the $\mathrm{ZnO}$ NWs have a positive value of the piezoelectric coefficient $\left(d_{33}\right)$, the value for the PVDF gives a negative value when polarized [49]. Nevertheless, in a tri-layer based configuration similar to the one presented here ( $\mathrm{ZnO}$ $\mathrm{NWs} / \mathrm{PVDF} / \mathrm{ZnO} \mathrm{NWs}$ ) the PVDF was poled to achieve maximum harvested output power $[52]$. 


\subsection{References}

[1] M. Willander, O. Nur, Q. X. Zhao, L. L. Yang, M. Lorenz, B. Q. Cao, J. Z. P_erez, C. Czekalla, G. Zimmermann, M. Grundmann, A. Bakin, A. Behrends, M. Al-Suleiman, A. El-Shaer, A. C. Mofor, B. Postels, A. Waag, N. Boukos, A. Travlos, H. S. Kwack, J. Guinard, D. L. S. Dang, Nanotech., 20 (2009) 332001 .

[2] Z. L. Wang, Mat. Sci. and Eng. R, 64 (2009) 33.

[3] O. Dulub, L.A. Boatner, U. Diebold, Surf. Sci., 519 (2002) 201.

[4] B. Meyer, D. Marx, Phys. Rev. B, 67 (2003) 035403.

[5] P. W. Tasker, J. Phys. C: Sol. Sta. Phys., 12 (1979) 4977.

[6] O. Dulub, U. Diebold, G. Kresse, Phys. Rev. Lett., 90 (2003) 016102.

[7] A. Wander, F. Schedin, P. Steadman, A. Norris, R. McGrath, T.S. Turner, G.Thornton, N.M. Harrison, Phys. Rev. Lett., 86 (2001) 3811.

[8] V. Staemmler, K. Fink, B. Meyer, D. Marx, M. Kunat, S. Gil Girol, U. Burghaus, Ch. Woll, Phys. Rev. Lett., 90 (2003) 106102.

[9] R. S. Yang, Y. Ding, Z. L. Wang, Nano Lett., 4 (2004) 1309.

[10] Y. Ding, X.Y. Kong, Z. L. Wang, Phys. Rev. B, 70 (2004) 235408.

[11] B. Wen, J. E. Sader, J. J. Boland, Phys. Rev. Lett., 101 (2008) 175502.

[12] Z. L. Wang, J. H. Song, Sci., 312 (2006) 242.

[13] M. Riaz, J. Song, O. Nur, Z. L. Wang, M. Willander, Adv. Fun. Mat., 20 (2010) 1.

[14] M. Y. Soomro, I. Hussain, N. Bano, O. Nur, M. Willander, Phy., Sta., Sol., (RRL), 6 (2012) 80.

[15] H. Ni, X. Li, Nanotech., 17 (2006) 3591.

[16] M.P. Lu, J. Song, M.Y. Lu, M.T. Chen, Y. Gao, L.J. Chen, Z.L. Wang, Nan.Lett., 9 (2009) 1223.

[17] E. Broitman, M. Y. Soomro, J. Lu, M. Willander, L. Hultman, Phy.Ch.Ch.Phy., 15 (2013) 11113.

[18] J. Briscoe, N. Jalali, P. Woolliams, M. Stewart, P. M. Weaver, M. Cain, S. Dunn, Ener. Environ. Sci., 6 (2013) 3035.

[19] E. S. Nour, A. Echresh, X. Liu, E. Broitman, M. Willander, O. Nur, AIP Adv., 5 (2015) 077163.

[20] Z. L. Wang, Adv. Fun. Mat., 18 (2008) 3553.

[21] Z. L. Wang, W. Wu. Angew. Chem. Int. Ed., 51 (2012) 11700.

[22] P. G. Gao, J. H. Song, J. Liu, Z. L. Wang, Adv. Mat., 19 (2007) 67.

[23] Z. L. Wang, Adv. Mat., 19 (2007) 889.

[24] J. H. Song, X. D. Wang, J. Liu, H. B. Liu, Y. L. Li, Z. L. Wang, Nano Lett., 8 (2008) 203.

[25] M. P. Lu, J. H. Song, M. Y. Lu, M. T. Chen, Y. F. Gao, L. J. Chen, Z. L. Wang, Nano Lett., 9 (2009) 1223. 
[26] J. Song, J. Zhou, Z. L. Wang, Nano Lett., 6 (2006) 1656.

[27] S. Xu, Y. Qin, C. Xu, Y. Wei, R. Yang, Z. L. Wang, Nat. Nanotechn., 5 (2010) 366.

[28] Y. Qin, X. Wang, Z. L. Wang, Nat., 451 (2008) 809.

[29] C. L. Hsu, K. C. Chen, Jour. of Phy. Chem. C, 116 (2012) 9351.

[30] S. Xu, Y. Wei, J. Liu, R. Yang, Z. L. Wang, Nano Lett., 8 (2008) 4027.

[31] A. Khan, M. A. Abbasi, M. Hussain, Z. H. Ibupoto, J. Wissting, O. Nur, M. Willander, App. Phy. Lett., 101 (2012) 193506.

[32] A.V. Desai, M.A. Haque, Sen. and Actuators A, 134 (2007) 169.

[33] Z. L. Wang, Mat. Tod., 10 (2007) 20.

[34] Ü. Özgür, Ya. I. Alivov, C. Liu, A. Teke, M. A. Reshchikov, S. Doan, V. Avrutin, S. J. Cho, H. Morkoç, JAP, 98 (2005) 041301.

[35] D. Florescu, L. G. Mourok, F. H. Pollack, D. C. Look, G. Cantwell, X. Li, JAP, 91 (2002) 8902.

[36] S. J. Pearton, D. P. Norton, K. Ip, Y. W. Heo, T. Steiner, Progress in Mat. Sci., 50 (2005) 293.

[37] J. Zhang, Z. Zhang, T. Wang, Chem. Mat., 16 (2004) 768.

[38] K. Subannajui, D. S. Kim, M. Zacharias, JAP, 104 (2008) 014308.

[39] H. Morkoc, U. Ozgur, WILEY-VCH Verlag, (2009) 1.

[40] F. Jones, F. Leonard, A. A. Talin, N. S. Bell, JAP, 102 (2007) 014305.

[41] D. Seghier, H. P. Gislason, Jou. of Mat. Sci. - Mat. in Elect., 19 (2008) 687.

[42] Y. Yang, H. Zhang, Z-H. Lin, Y. S. Zhou, Q. Jing, Y. Su, J. Yang, J. Chen, C. Hu, Z. L. Wang, ACS Nano, 7 (2013) 9213.

[43] X. Wang, J. Song, J. Liu, Z. L. Wang, Sci., 316 (2007) 102.

[44] E. S. Nour, A. Bondarevs, P. Huss, M. Sandberg, S. Gong, M. Willander, O. Nur, Nanoscale Res. Lett., 11 (2016) 156.

[45] E. S. Nour, C. O. Chey, M. Willander, O. Nur. Phy. Sta. Sol., 26 (2016) 095502.

[46] E. S. Nour, C. O. Chey, M. Willander. O Nur. Nanotech., 26 (2015) 095502.

[47] A. Vinogradov, F. Holloway, Ferroelectrics, 226 (1999) 169.

[48] R. G. Kepler, R. A. Anderson, JAP, 8 (1978) 49.

[49] M. Lee, C-Y. Chen, S. Wang, S. N. Cha, Y. J. Park, J. M. Kim, L-J. Chou, Z. L. Wang, Adv. Mat., 24 (2012) 1759.

[50] Y. Hao, T. Huang, M. Lu, M. Mao, Q. Zhang, H. Wang, Nanotech., 24 (2013) 405401.

[51] Y. Gao, Z. L. Wang, Nano Lett., 7 (2007) 2499.

[52] E. S. Nour, M. O. Sandberg, M. Willander, O. Nur, Nano Ener., 9 (2014) 221. 



\section{Chapter three: Synthesis of nanostructured materials and device processing}

This chapter describes the details of the experimental procedures used to synthesize $\mathrm{ZnO}$ nanostructures (NSs) with good quality. The aim was to attain reproducible NSs with uniform morphology and controllable spatial distribution. Those procedures were based on the low temperature hydrothermal wet chemical routine by using the one step growth protocol technique. Then those NSs were used to fabricate functional devices such as nanogenerators (NGs), piezoelectric sensors etc. to develop proto-type self-powered systems.

\subsection{Substrate treatment}

The substrates used in the present thesis were treated before synthesizing the NSs. This treatment process plays an important role in the morphology and quality of the grown NSs. there are a number of important steps that have to be performed before the synthesis of the NSs in the wet chemical synthesis procedure we adopted. These steps include the selection and the cleaning method of the substrate, deposition of a thin conductive layer and the preparation of the seed nanoparticles (NPs). This is followed by spin coating of these seed nanoparticles on the substrate then a pre growth annealing is performed. However, adjusting these parameters plays a significant role in the quality of the final product synthesized NSs.

\subsubsection{Substrate cleaning}

In order to eliminate/remove the dust or metallic contaminants or any other particles, we must always clean the substrate. This step plays an important role to enable us to obtain the desired properties such as uniformity, high quality and well aligned NSs, etc.. This in addition to the reproducibility. The cleaning has been performed by immersing the substrates in acetone and isopropanol respectively for 2 minutes each. Finally deionized (DI) water was used to flush the samples and nitrogen flow was used for drying the samples.

\subsubsection{Thin films deposition}

After the cleaning of the substrate, usually a conducting material is deposited on the substrate. This material can be a metal, metal oxide semiconductor or polymer e.g. silver $(\mathrm{Ag})$, gold $(\mathrm{Au})$ lor Aluminum (Al), PEDOT:PSS, ITO etc.. So, in our processes mostly metal thin films were thermally evaporated using a Satis metal evaporator under a relatively low pressure of $\left(2.5 \times 10^{-6} \mathrm{mbar}\right)$. Usually a $10-20 \mathrm{~nm}$ thickness thin film of chromium $(\mathrm{Cr})$ is first deposited on the substrates to improve the adhesion properties of the conducting metal to be deposited. Then a 50-150 $\mathrm{nm}$ of the appropriate conducting metal thin film is evaporated. 


\subsubsection{Preparation of $\mathrm{ZnO}$ seed solution}

There are many different approaches to prepare the seed solution containing the NPs. In this work we follow the Greene et. al. [1] approach procedure. The seed layer was prepared by dissolving zinc acetate dehydrate $\left(\mathrm{Zn}(\mathrm{CH} 3 \mathrm{COO})_{2}\right.$. 2H2O) in high purity methanol $(99 \%)$ leading to $0.01 \mathrm{M}$ concentration. Then this solution was annealed at $60{ }^{\circ} \mathrm{C}$ on a hotplate. A solution of potassium hydroxide $(\mathrm{KOH})$ in methanol (prepared separately) was added dropwise to the $\mathrm{Zn}$ acetate solution. Stirring was applied all the time, keeping the temperature at $60{ }^{\circ} \mathrm{C}$ for a duration of about two hours. The prepared solution is expected to contain dispersed $\mathrm{ZnO}$ NPs with an average size of 3-5 $\mathrm{nm}$. After this, the solution is then ready to be used for spin coating on the substrate $[2,3]$.

\subsubsection{Deposition of seed solution}

In the synthesis process we adopted, the $\mathrm{ZnO}$ NSs preferentially nucleate and grow at the seed layer sites. The density of the NPs in turn can be used as a way to control the density and placement of the grown $\mathrm{ZnO}$ NSs. By controlling the spinning speed of the seed layer, one can control the thickness of the seed layer and its surface coverage. In order to supply nucleation sites the NPs act to optimize the thermodynamic barrier between the heterogeneous materials $[3,4]$ and to obtain NSs with the desired properties. In our process, a few drops of the seed solution were dropped onto the substrate and the substrate was spun at $3000 \mathrm{rpm}$ running speed using a Laurell WS-650-8B spin coater. The process was repeated three times for 30 seconds each time. However, controlling the spin speed will affect on the thickness of the seed layer. Furthermore, the $\mathrm{ZnO}$ seed layer properties are critical for the final product morphology e.g. how uniform and vertically aligned [1].

\subsubsection{Post seed layer deposition processing}

The annealing process is used to ensure that the seed NPs are attached to the substrate. Usually, the substrate is heated for a specific duration (5-10 minutes) at a temperature of around $100{ }^{\circ} \mathrm{C}$ [5]. The annealing process helps to form a uniform crystalline and aligned $\mathrm{ZnO}$ NSs. It is of interest to note that such a low temperature process permits the utilization of flexible and soft substrates like e.g. paper, textile, etc.. [6-9].

\subsection{Hydrothermal synthesis of nanostructures}

At present, the hydrothermal chemical methods are considered as one of the most popular and promising techniques due to the fact that the morphology, structure, and hence properties, can all be controlled by tuning the growth conditions. This is addition to the low cost and ease of fabrication, being environmentally friendly, and diverse NSs can be achieved and in addition the low temperature enables the growth on any flexible and foldable substrate [6-11]. The properties of nanomaterials and the associated application are affected by the morphology, the hydrothermal chemical methods provide broad possibilities for adjustments of the 
morphology achieved and hence these chemical methods have become attractive [12, 13]. This is in addition to the possibility of scaling-up the processes to suit industrial production.

\subsubsection{Synthesis of $\mathrm{ZnO}$ nanowires/nanorods (NWs/NRs)}

Many efforts have been executed to study the conditions and synthesis of NSs using the hydrothermal process. Starting with the precursor solution, which is usually prepared by mixing of $100-150 \mathrm{mM}$ of zinc nitrate hexahydrate $\left(\mathrm{Zn}(\mathrm{NO} 3)_{2} \cdot 6 \mathrm{H}_{2} \mathrm{O}\right)$ and $100 \mathrm{mM}$ of hexamethylenetetramine $\left(\mathrm{C}_{6} \mathrm{H}_{12} \mathrm{~N}_{4}\right.$, HMTA), with a volume ratio of $1: 1$ or $1.5: 1$, respectively. It is widely accepted that the addition of HMTA to the aqueous solution of zinc nitrate regulates the solution $\mathrm{pH}$ value and supplies addition $\mathrm{OH}^{-}$ions $[14,15]$. Moreover, in [16] A. Sugunan et. al. proposed that the HMTA is preferably attached to the non-polar surface of the zincate crystal and this means preventing the access of $\mathrm{Zn}^{2+}$ ions to reside on the sides of the structure, leaving the $\mathrm{Zn}^{2+}$ ions access only to the polar facet (0001) for further nucleation and vertical growth. The prepared aqueous solution is then vigorously stirred for 20-30 minutes to ensure that the precursor materials are completely dissolved. The hydrothermal synthesis of ZnO NSs scheme is shown in Figure (3.1). The pre-seeded substrates using the procedure described in section (3.1.3) were spun coated and then immersed into the nutrient solution. The nutrient solution containing the pre-coated substrate was then transferred to a conventional oven and held at $\left(80-90^{\circ} \mathrm{C}\right.$ ) for several hours (usually 5-6 hrs.). After that, the samples were collected and then were washed carefully with DI-water to remove unreacted salts, resulting in c-axial oriented ZnO NSs i.e. nanowires/ nanorods (NWs/ NRs).

The growth process of the $\mathrm{ZnO}$ NSs controlled by the chemical reactions involved and are summarized as follows [3, 11, and 16]. In the hydrothermal method, the dissolved zinc nitrate provides the $\mathrm{Zn}^{2+}$ ions and the water molecules in the solution provide the $\mathrm{O}^{2-}$ ions. These are the two main ions that are needed to synthesize the ZnO NWs. The HMTA has an important role in achieving the morphology of NWs/ NRs. The vertical growth of NWs/ NRs is due the passivation effect when using the HMTA. This is in addition to its weak basic nature that lead to hydrolysis during the synthesis process. As the HMTA hydrolyzes and produces $\mathrm{OH}^{-}$very fast, it leads to quick precipitation of the $\mathrm{Zn}^{2+}$ ions to form $\mathrm{ZnO}$ crystal.

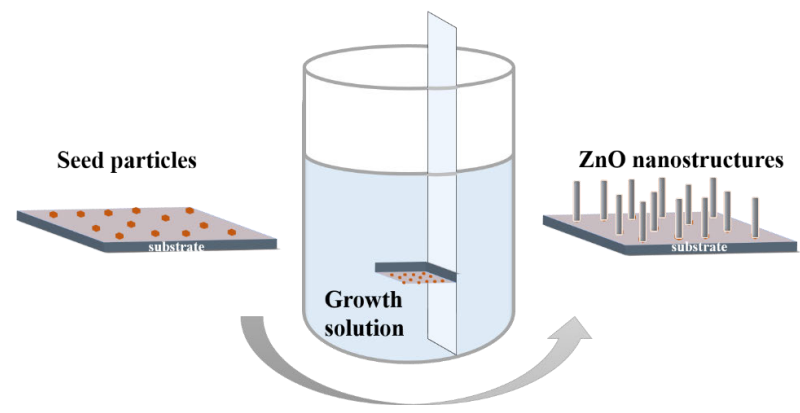

Figure 3-1: Schematic diagram of the synthesis of ZnO NSs using the hydrothermal method. 
The chemical reactions involved can be summarized as [3, 11 and 16]:

$$
\begin{aligned}
& \left(\mathrm{CH}_{2}\right)_{6} \mathrm{~N}_{4}+6 \mathrm{H}_{2} \mathrm{O} \leftrightarrow 4 \mathrm{NH}_{3}+6 \mathrm{HCHO} \\
& \mathrm{NH}_{3}+\mathrm{H}_{2} \mathrm{O} \leftrightarrow \mathrm{NH}_{3} \cdot \mathrm{H}_{2} \mathrm{O} \\
& \mathrm{NH}_{3} \cdot \mathrm{H}_{2} \mathrm{O} \leftrightarrow \quad \mathrm{NH}_{4}^{+}+\mathrm{OH}^{-} \\
& \mathrm{Zn}^{2+}+2 \mathrm{OH}^{-} \leftrightarrow \quad \mathrm{Zn}(\mathrm{OH})_{2}
\end{aligned}
$$

The $\mathrm{Zn}(\mathrm{OH})_{2}$ is a metastable compound that de-hydrolyzes under the given conditions to produce $\mathrm{ZnO}$ according to:

$$
\mathrm{Zn}(\mathrm{OH})_{2} \stackrel{\Delta}{\rightarrow} \mathrm{ZnO}+\mathrm{H}_{2} \mathrm{O} \quad(3-5)
$$

The above reactions (3-1 to 3-5) represent cases of equilibrium reactions. They can all be tuned by adjusting the different synthesis parameters like temperature, concentration, $\mathrm{pH}$ value etc.. The density of the grown NWs/ NRs is generally specified by the concentration of the reactants, while the reaction temperature and duration can precisely be used to control the aspect ratio (length/diameter) [3, 11].

\subsubsection{Synthesis of Ag doped $\mathrm{ZnO}$ NRs}

For the growth of the $\mathrm{Zn}_{1-\mathrm{x}} \mathrm{Ag}_{\mathrm{x}} \mathrm{O}$ NRs (with $\mathrm{x}=0,0.03,0.06$ and 0.09), an equimolar concentration $(0.075 \mathrm{M})$ of hexamethylenetetramine (HMTA), and a mixture of zinc nitrate hexahydrate and silver nitrate solutions ready to combine. The different Ag concentrations were obtained by mixing different volume ratios of the zinc nitrate hexahydrate and silver nitrate. Next, the pre-seeded substrates using the procedure described above were spun coated, fallowed by immersing the substrate into the nutrient. Then, the beaker was sealed and heated in a laboratory oven at around $90{ }^{\circ} \mathrm{C}$ for 6 hours [17]. After that, the growth beaker was allowed to cool down to room temperature. Finally, the samples were collected and washed carefully with DI-water to remove unreacted salts.

\subsection{Nanogenerator device processing}

After synthesizing the growth of NWs/ NRs, we fabricated the devices by gently pressing different top contacts on the top of $\mathrm{ZnO} \mathrm{NWs} / \mathrm{NRs}$ grown on a substrate, such as coated silver paper, silver coated plastic, gold coated plastic, thin aluminum foil. This is followed by careful sealing of the device before performing the measurements. 
For the fabrication of these NGs and sensor devices, different configurations of the different layers were designed and studied (see Figure 3-2). The aim was to demonstrate configurations that providing the highest harvested out-put power under different low frequencies mechanisms $(<100 \mathrm{~Hz})$. Finally, we introduced the fabrication of the NGs with different energy harvesting mechanisms. The fabricated devices, functioned as a NG, a wireless triggered sensor, an accelerator sensor, and directional sensor, all as active components in a self-powered system.

(a)

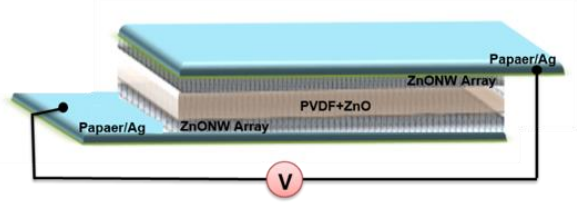

(b)

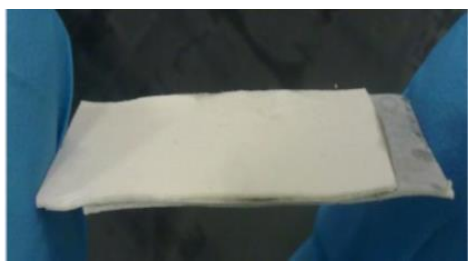

Figure 3-2: (a) Schematic diagram showing the structure of the general configuration used for the piezoelectric NG. (b) A digital photograph of the final fabricated NG. 


\subsection{References}

[1] L. E. Greene, M. Law, D. H. Tan, M. Montano, J. Goldberger, G. Somorjai, Nano Lett., 5 (2005) 1231.

[2] C. Pacholski, A. Kornowski, H. Weller, Ange. Chem. Inter. Edition, 41 (2002) 1188.

[3] A. Zainelabdin, S. Zaman, G. Amin, O. Nur, M. Willander, Cryst Gro. Des., 10 (2010) 3250.

[4] D. S. Boyle, G. K. Ovender, P. O’Brien, Chem. Comm., 14 (2002) 80.

[5] T. M. Brseth, PhD thesis, University of Oslo, (2007).

[6] E. S. Nour, M. O. Sandberg, M. Willander, O. Nur, Nano Ener., 9 (2014) 221.

[7] E. S. Nour, A. Bondarevs, P. Huss, M. Sandberg, S. Gong, M. Willander, O. Nur, Nanoscale Res. Lett., 11 (2016) 156.

[8] E. S. Nour, C. O. Chey, M. Willander. O Nur, Nanotech., 26 (2015) 095502.

[9] A. Khan, M. A. Abbasi, M. Hussain, Z. H. Ibupoto, J. Wissting, O. Nur, M. Willander, App. Phy. Lett., 101 (2012) 193506.

[10] G. Amin, M.H. Asif, A. Zainelabdin, S. Zaman, Nur O, M. Willander, J. of Nanomat., 2011 (2011) 269692.

[11] S. Xu, Z. L. Wang, Nano Res., 4 (2011) 1013.

[12] S-F. Wang, T-Y. Tseng, Y-R. Wang, C-Y. Wang, H-C. Lu, W-L. Shih, Int. J. Appl. Ceram. Technol., 5 (2008) 419.

[13] C. Sun, D. J. Xue, Phys. Chem. C, 117 (2013) 5505.

[14] L. Vayssieres, Adv. Mat., 15 (2003) 464.

[15] L. Vayssieres, K. Keis, A. Hagfeldt, S. E. Lindquist, Chem. of Mat., 13 (2001) 4395.

[16] A. Sugunan, H. Warad, M. Boman, J. Dutta, Journal of Sol-Gel Sc. and Tec., 39 (2006) 49.

[17] E. S. Nour, A. Echresh, X. Liu, E. Broitman, M. Willander, O. Nur, AIP Adv., 5 (2015) 077163. 


\section{Chapter four: Characterization tools and techniques}

Different analytical tools were used to characterize the material structure, morphology and properties. Scanning electron microscopy (SEM), x-rays diffraction (XRD) technique using Bragg-Brentano geometry, photoelectron Spectroscopy (XPS) and nanoindentaion equipment were all used to study the structure, morphology and surface properties. While, Ultravioletvisible spectroscopy (UV-vis), Keithley 2400 and FET station 4200-SCS semiconductor characterization systems were used to study the optical and electro-mechanical properties of the fabricated energy harvesting different devices.

\subsection{Structural and morphology characterization studies}

\subsubsection{X-rays diffraction (XRD)}

X-rays diffraction (XRD) is a powerful structural characterization technique used to investigate the crystalline structures. It is a non-destructive analytical technique that provides unprecedented detailed information of the crystal structures, orientations, size, unit cell lattice parameters, phases and chemical composition of materials. All types of materials being nanostructures (NSs), thin films or in the bulk form can be studied using x-ray. The working principle of the XRD technique is simple. X-ray works as follows: a monochromatic characteristic $\mathrm{X}$-rays is generated by the effect of accelerated electrons with a heavy metal such as copper $(\mathrm{Cu})$, which then gets filtered and collimated by a filter.

A constructive interference can be observed when x-rays (with a wavelength $(\lambda)$ ) fall on a crystal lattice at an angle $\theta$. The Bragg's law states:

$$
\mathrm{n} \lambda=2 \mathrm{~d}_{\mathrm{hkl}} \sin (\theta)
$$

where $\mathrm{n}$ is an integer $1,2,3 . ., \quad \lambda$ is wavelength in angstroms $(1.5418 \AA)$, and dhkl is the inter plan spacing between the (hkl) set of planes.

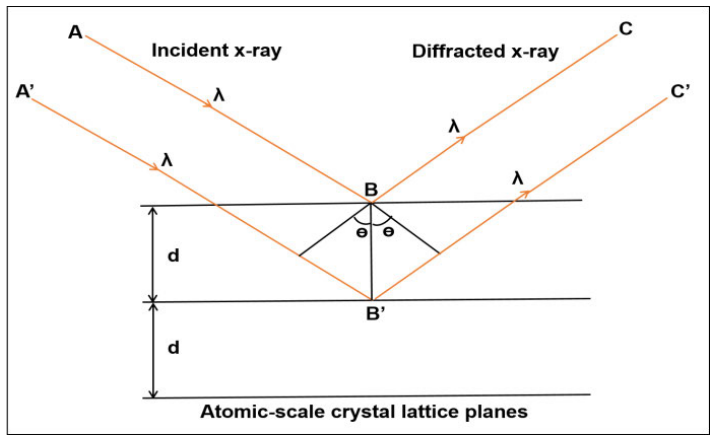

Figure 4-1: Bragg's Law reflection. The diffracted x-rays exhibit constructive interference when the distance between paths $\mathrm{ABC}$ and $\mathrm{A}^{\prime} \mathrm{B}^{\prime} \mathrm{C}^{\prime}$ differs by an integer no. of the wavelengths $(\lambda)$. 


\subsubsection{Scanning electron microscope (SEM)}

The Scanning electron microscope (SEM) is a structural characterization tool that is considered as being very useful in yielding information about the morphology of materials and their surface characteristics. SEM used to support information about the surfaces such as quality, shape, density, diameter, thickness, length and orientation/direction of the grown NSs. As for our work, we used SEM (model LEO 1550 Gemini microscope) running at 15 $\mathrm{kV}$. The SEM provides images by scanning the surface through an electron beam focused using electric and magnetic lenses aligned carefully to provide a beam with specific energy and intensity. The lenses are used to collect and focus the electrons beam, carefully without and destroying. Then the scattered beams are also gathered by a detector and send the sign out to the displaying screen [2].

\subsubsection{X-rays photoelectron spectroscopy (XPS)}

The chemical composition at or close to the surface $(0-10 \mathrm{~nm})$ of a sample can be studied using X-ray photoelectron spectroscopy (XPS). It is also used to determine the chemical or electronic state of each chemical element on a detailed level and is useful to study the energy distribution from the emitted electrons at the surface [3]. Through this technique, one can measure the kinetic energy of photoelectrons to determine the binding energy, intensity and angular distributions of these electrons. Then this information is further used to examine the electronic structure of molecules. Conceptually, in the case of radiation by high energy incident $\mathrm{x}$-ray photon, typical XPS spectra will be produced. A core electron will escape from the atom at the surface of the sample when the energy of the $\mathrm{x}$-rays is high enough. This emitted electron will have a specific kinetic energy when leaving the surface. In this case the emitted electron is known as a photoelectron. Usually only electrons on or near (inside the material and deep down to $0-10 \mathrm{~nm}$ ) to the surface can be emitted [3]. Since the total x-ray energy is known, and the kinetic energy of the emitted electron can be observed, therefore the binding energy of the emitted electron can be extracted from the equation below [3]:

$$
\begin{array}{ll}
\mathrm{E}_{\mathrm{b}}=\mathrm{E}_{\text {phot }}-\left(\mathrm{E}_{\mathrm{k}}+\Phi_{\text {spect }}\right) & (4-2) \\
\mathrm{E}_{\mathrm{k}}=\mathrm{hv}-\mathrm{E}_{\mathrm{b}}-\Phi_{\text {spect }} & (4-3)
\end{array}
$$

where $\left(E_{b}\right)$ is the binding energy (B. E.) of the atomic orbital from which the electron originates, $\left(E_{\text {phot }}\right)$ is the energy of the x-ray photons being used, $\left(E_{k}\right)$ is the measured kinetic energy of the electron and ( $\left.\Phi_{\text {spect }}\right)$ is the work function dependent on both the spectrometer and the material. The XPS spectrum describes the number of detected electrons versus their binding energy. XPS is utilized to precisely study the elements concentration on the sample surfaces, because of a specific XPS peak is generated from each sample at cretin binding energy. The chemical state of the materials can hence be obtained since core electrons of each material have a specific characteristic binding energy [3]. 


\subsubsection{Nanoindentation}

The atomic force technique (AFM) is qualifying to be nanoindentation, where a cantilever device (called hysitron triboscope) is used to substitute the AFM. This nanoindentation device is utilized to study the different electormechanical properties of the materials [4-7]. As for our work, a Triboindenter TI-950 (Hysitron) with a conductive boron-doped diamond Berkovich tip was used to perform our nanoindentation measurement. Electronic properties of the fabricated devices were characterized by current-voltage measurements using a semiconductor parameter analyzer and $\mathrm{C}-\mathrm{V}$ measurements. The (I-V) measurements were performed using semiconductor parameter analyzer (HP/ Agilent 4145B) by placing the sample in a probe station. For temperature dependent I-V curves we used a cryogenic probe station attached with a supply of liquid nitrogen. Figure 4-2 shows an illustration of the nanoindentaion test for the (a) direct and (b) converse piezoelectric effect.

Coupling mechanical and electrical characterization in one technique like the nanoindentation technique enables accurate study regarding the effect of the external applied mechanical force and the materials deformation behavior [8].

(a)

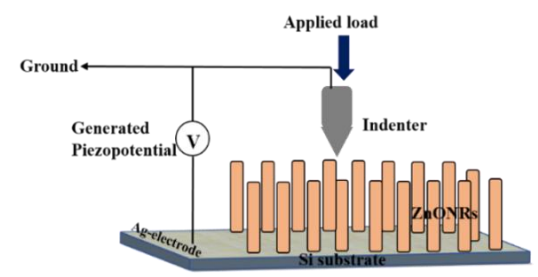

(b)

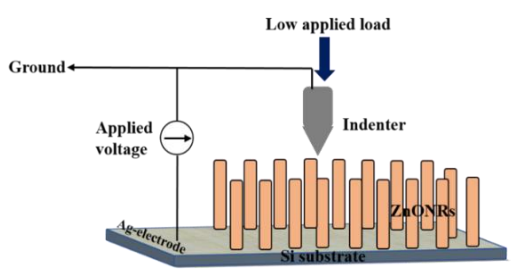

Figure 4-2: Graphical illustration of the nanoindentaion test for the (a) direct and (b) converse piezoelectric effect.

Typically, the information provided by the Hysitron's nanoindentation are improves at the experiment time. A wealth of electormechanical information about the material under investigation can be obtained using the Hysitron nanoindentation technique. The technique relies on the passage of current through the probe/sample contact, and measure the accompanied mechanical effects. Or applying a specific force and then measure the voltage [8]. By combining electrical and nanoindentation measurements a wide range of information like e.g. stress induced phase transformation materials can for example be determined. This is in addition to, many important properties like e.g. dielectric behavior, contact resistance evaluation etc.. [8]. 


\subsection{Optical characterization}

\subsubsection{Ultra-Violet-Visible spectroscopy}

Ultraviolet-visible spectroscopy (UV-vis) is an important analytical tool. UV-vis has two modes. The first is absorption mode and the second is reflectance mode, both are achieved for the ultraviolet-visible range i.e. between a wavelengths of 200 to $800 \mathrm{~nm}$. The electronic transitions due to absorption of photons (either for ground, or for higher energy or excited state) is obtained since the absorption versus wavelength is recorded [9]. The absorbance A is simple expressed as Beer's law:

$$
A=\log \left(\frac{\mathrm{I}}{\mathrm{I}_{0}}\right)
$$

where the transmittance is denoted by the ratio $\frac{I}{I_{0}}$, I is the light intensity, and $\mathrm{I}_{0}$ is the intensity of light before entering the sample. In this thesis results, we estimated the optical band gap of our synthesized nanomaterial using [10]:

$$
\alpha=\left(\frac{\mathrm{K}}{\mathrm{hv}}\right)\left(\mathrm{hv}-\mathrm{E}_{\mathrm{g}}\right)^{\beta} \quad(4-5)
$$

where $\alpha=2.303 \times\left(\frac{A}{d}\right)$ is the absorption coefficient, $d$ is thickness of the sample, $\beta=1 / 2$ for direct band gap semiconductors and $k=\alpha \lambda / 4 \pi$ is the extinction coefficient, $h$ is Planck's constant and $\mathrm{h} v$ is the incident photon energy [11].

$$
\begin{array}{ll}
\alpha=\left(\frac{\mathrm{K}}{\mathrm{hv}}\right)\left(\mathrm{hv}-\mathrm{E}_{\mathrm{g}}\right)^{1 / 2} & (4-6) \\
(\alpha h v)^{2}=\mathrm{C}\left(\mathrm{hv}-\mathrm{E}_{\mathrm{g}}\right) & (4-7)
\end{array}
$$

Using the interception of the linear portion with the $\mathrm{x}$-axis of $(\alpha h v)^{2}$ versus (hv) curve; the sample's optical energy gab can be estimated.

\subsection{Electrical measurements}

The electrical and electrochemical characterizations of the devices were performed by several tools such as Keithley, I-V semiconductor parameter analyzer, digital storage oscilloscope DSO-X 2012A and FET Station. Keithley 2400 source-meter were also used to measure the voltage (current) responses of the energy harvesting devices. However, the measurements data was transferred to a computer screen using Lab-View program. While the semiconductor parameter analyzer, which is the basic equipment that has been used to study the electrical properties of semiconductor devices by registering the I-V data of the energy harvesting devices. Finally, a digital storage oscilloscope DSO-X 2012A and a FET Station 4200-SCS semiconductor characterization system were also used. 


\subsection{References}

[1] G. Will, Springer Berlin Heidelberg, (2006) 1; Providing Solutions To Your Diffraction Needs, Scintag Inc, (1999) 7. 1.

[2] W. Zhou, R. Apkarian, Z. L. Wang, D. Joy, Springer New York, (2007).

[3] J. Chastain, C. Roger, Jr. King, Physical Electronics USA, (1995) 9.

[4] M. Riaz, A. Fulati, L. L. Yang, O. Nur, M. Willander, P. Klason, JAP, 104 (2008) 104306.

[5] M. Riaz, A. Fulati, G. Amin, N. H. Alvi, O. Nur, M. Willander, JAP, 106 (2009) 034309.

[6] M. Riaz, O. Nur, M. Willander, P. Klason, App. Phy. Lett., 92 (2008) 103118.

[7] M. Riaz, A. Fulati, Q. X. Zhao, O. Nur, M. Willander, P. Klason, Nanotech., 19 (2008) 415708.

[8] https://www.hysitron.com/techniques-properties/electro-mechanical-properties.

[9] Z. Chen, H. Dinh, E. Miller, Springer Briefs in Energy Ed, (2013) 49.

[10] N. Shakti, P. S. Gupta, App. Phy. Res., 2 (2010) 19.

[11] P. Sharma, K. Sreenivas, K. V. Rao, JAP, 93 (2003) 3963. 



\section{Chapter five: Results and discussion}

This chapter discusses the results achieved during the course of this research. Starting with the fabrication a piezoelectric nanogenerator (NG) on paper substrate (Paper I) and then developing this NG to work as a triggered sensor for wireless system (Paper II). After that, we fabricated a piezoelectric different sensor on plastic substrate, either by using a one sided growth technique to function as an accelerometer system (Paper III) or by using a double sided growth approach which is then work as an isotropic direction detector (Paper IV). In addition to that, we investigated the fabrication of different sandwiched NGs on plastic substrates (Paper V), the aim here was to maximize the harvested piezoelectric output through different configurations. Finally, we studied the electromechanical properties of $\mathrm{ZnO}$ nanorods (NRs) doped with silver (Paper VI). All the samples for this paper were synthesized using the low temperature hydrothermal aqueous chemical method. Here we investigated the effect of altering the crystal symmetry of $\mathrm{ZnO}$ hexagonal structure by addition of Ag.

\subsection{Paper I: Handwriting Enabled Harvested Piezoelectric Power Using $\mathrm{ZnO}$ Nanowires/Polymer Composite on Paper Substrate}

Energy harvesting (or power scavenging) refers to capturing energy from environment, surrounding system or any other source and converting it into a usable form of energy to develop self-power system that doesn't need external power supply e.g. piezoelectric process [1-4]. In this work, we have demonstrated a handwriting enabled energy harvesting device based on a thin silver layer coated paper substrate. SEM image of the $\mathrm{ZnO}$ nanowires (NWs) grown hydrothermally on paper substrate is shown in Figure 5-1 (a).

(a)

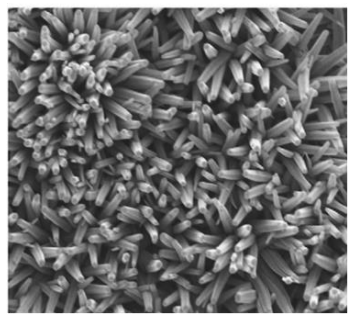

(b)

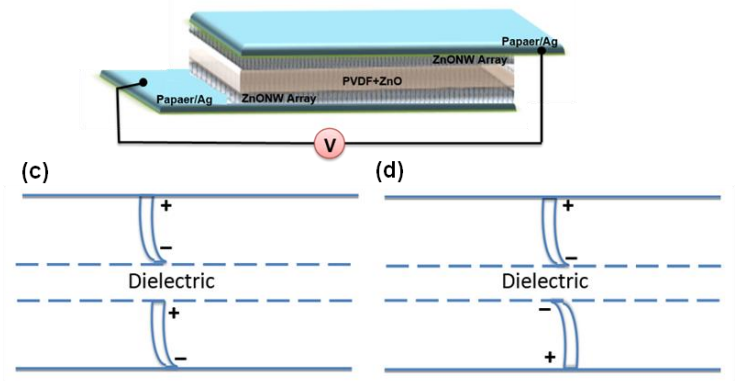

Figure 5-1: (a) SEM image of the $\mathrm{ZnO}$ nanowires (NWs) grown on paper substrate. (b) Shows a schematic diagram displaying the structure of the general configuration used for the present piezoelectric NG. (c) Schematic diagram illustrating different possibilities of the ZnO NWs bending due to pressure exerted while handwriting is applied. The expected voltage polarity on the paper contact (top and bottom) is also shown.

The device configuration is basically a tri-layer configuration. After the synthesize of the $\mathrm{ZnO}$ NWs on paper substrate, an ink composed of $\mathrm{ZnO}$ NWs and polyvinylidene fluoride- 
trifluoroethylene (PVDF-TrFE) was prepared by mixing the two components. This ink was pasted on the surface of the paper substrate using the stencil print approach. Then cut this paper into two parts and we attached them face to face as shown in Figure 5-1 (b). Electrical contacts were applied by attaching a crocodile contact to the two edges of each paper. Handwriting was then applied on one surface of the paper substrate. Two modes of low and high writing speeds were tested. The handwriting energy harvesting device was processed using $\mathrm{ZnO}$ NWs combined with a PVDF.

(a)

(b)
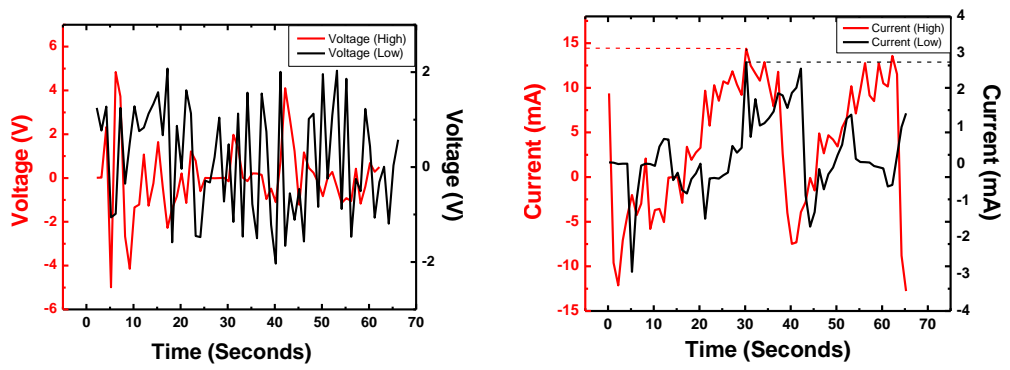

(c)

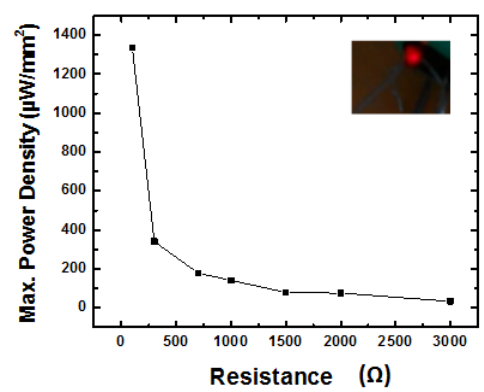

Figure 5-2: $(a, b)$ The output voltage/current achieved using $\mathrm{ZnO}$ NWs filtered powder as a function of time at low and high speed handwriting, respectively. (c) The maximum output power density as a function of the load resistance for a $\mathrm{NG}$ based on $\mathrm{ZnO} \mathrm{NWs}$ /PVDF polymer ink pasted and sandwiched between two pieces of paper with $\mathrm{ZnO}$ NWs grown chemically on one side of each piece of paper is shown [5]. The inset is a digital photograph showing a light emitting diode operated by handwriting harvested power from the handwriting enabled paper NG.

When no handwriting is applied i.e. no bending, then no c-axis potential gradient along the ZnO NWs will be observed. Nevertheless, when the NWs are bent, there will be two possible distinct situations. These two situations are illustrated in Figure 5-1 (c and d); the bending of the NWs leads to create a piezoelectric potential gradient in such a way that the top paper contact will have a positive potential while the bottom paper contact will have a negative potential as clear in Figure 5-2 (c). A situation similar to this but with reversed voltage polarity can also exist. In that case the harvested potential will be in the opposite direction to 
that of Figure 5-1 (c) is when similar voltage polarity exists at both top and bottom contacts. Assuming that the $\mathrm{ZnO}$ NWs are identical and upon handwriting they bent similarly, the harvested voltage from the top and bottom paper will cancel each other. This shown in Figure 5-1 (d),

(a)

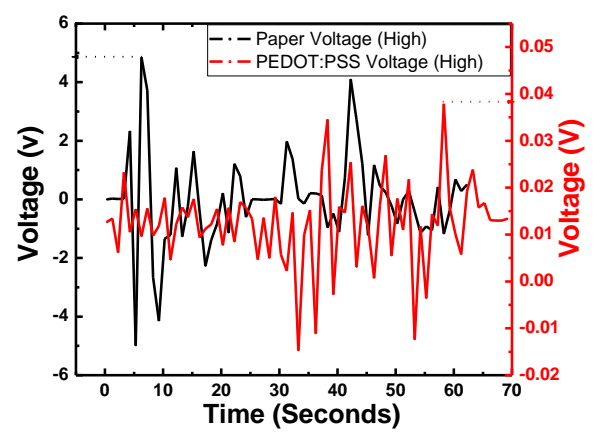

(b)

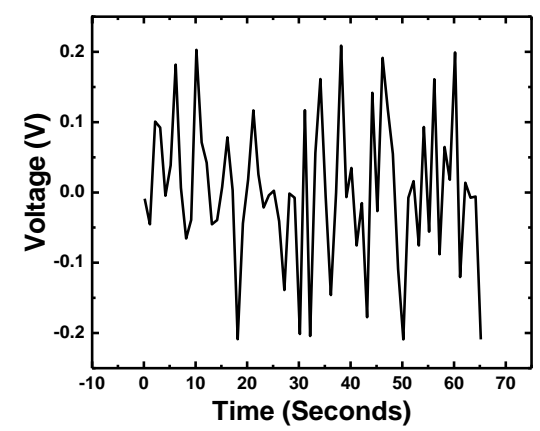

Figure 5-3: (a) The performance of $\mathrm{ZnO}$ NWs/PVDF NG fabricated on paper substrate and on PEDOT:PSS plastic platforms for comparison. (b) The open circuit output voltage as a function of time of a NG fabricated by pure polymer ink sandwiched between two $\mathrm{ZnO}$ NWs grown on paper.

The electrical open circuit output voltage for the configuration shown in Figure 5-2 (a) has a maximum value of $2.0 \mathrm{~V}$ for low speed handwriting while it has a maximum value of $4.8 \mathrm{~V}$ for high speed handwriting. While Figure 5-2 (b) shows the corresponding short circuit current value of $2.8 \mathrm{~mA}$ and $14.4 \mathrm{~mA}$ for low and high speed handwriting, respectively. The corresponding out power density was as high as $1.3 \times 10^{-3} \mu \mathrm{W} / \mathrm{mm}^{2}$ as shown in Figure $5-2$ (c).

To investigate the impact of the substrate, we have also fabricated a NG using our ink sandwiched between two ZnO NWs grown by the chemical methods on PEDOT:PSS coated plastic substrate. This device is shown on Figure 5-3 (a). The device based on paper substrate lead to an improvement of the output voltage by a factor of 100 compared to the case when using plastic as a platform for the device. Furthermore, we studied the effect of the ink composite components. We compared different NGs. A pure polymer ink with no ZnO nano powder, i.e. a sample with only pure PVDF sandwiched between two pieces of paper with $\mathrm{ZnO}$ NWs grown chemically on their surface is fabricated. This configuration showed relatively lower output voltage compared to the results of Figure 5-2 (a) where the ink is made from a composite of PVDF and powered $\mathrm{ZnO}$ NWs. This is shown in Figure 5-3 (b) where a maximum of $0.2 \mathrm{~V}$ was achieved when performing high speed handwriting [5].

The present piezoelectric NG provides a low cost and can be used for many applications, e.g. development of signature verification programmable smart paper, handwriting in dark paper when integrating light emitting diodes on the same paper etc.. Further it is important to mention that the process adopted is scalable and hence can be suitable for industrial production. 


\subsection{Paper II: Low-Frequency Self-Powered Footstep Sensor Based on $\mathrm{ZnO}$ Nanowires on Paper Substrate}

In this work, we designed and fabricated a triggered device for a wireless system with main operating device based on $\mathrm{ZnO}$ NWs. The main operating device is based on piezoelectric NG achieved using ZnO NWs grown hydrothermally on paper substrate as shown in the schematic diagram of Figure 5-4 (a). The fabricated NG that can harvest ambient mechanical energy from various kinds of human motion, e.g. footsteps [6].

The harvested electric output (voltage/current) from the device has been used as a pressure sensor that supply it's power (i.e. self-powered). The resulting output is shown in Figure 5-4 (b and c). A maximum output open circuit voltage and short circuit current values of about $1 \mathrm{~V}$ and $1 \mu \mathrm{A}$, respectively were obtained.

(a)

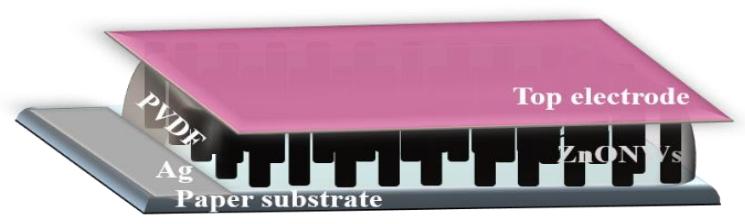

(b)

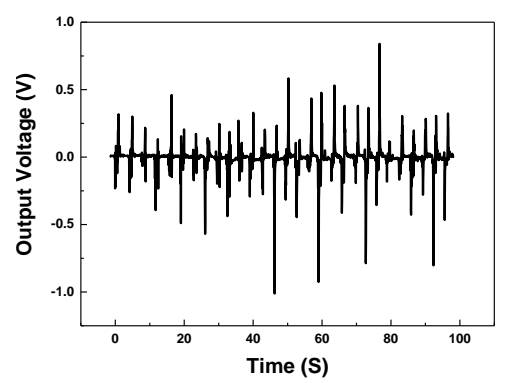

(c)

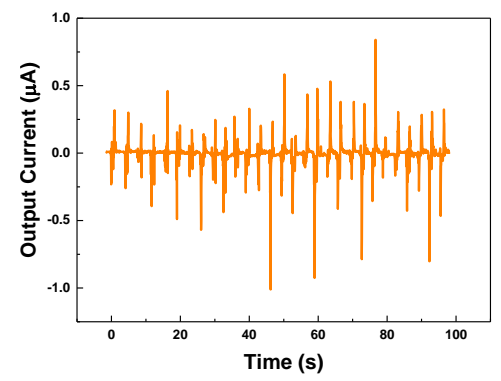

Figure 5-4: (a) Schematic diagram showing the NGs device. (b and c) The output voltage and current as a function of time, under repeated footsteps.

The device harvesting electric output has been used to serve as a self-powered pressure sensor. Without storing component, the signal from a single foot-step has been successfully used to trigger a wireless sensor node [6]. 
(a)

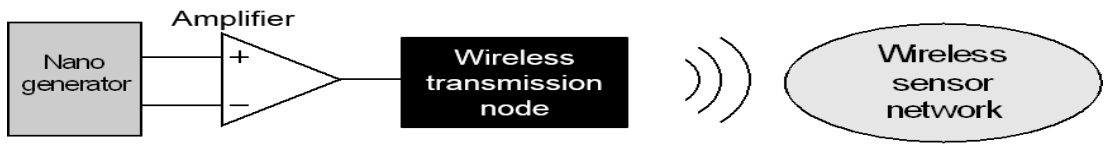

(b)

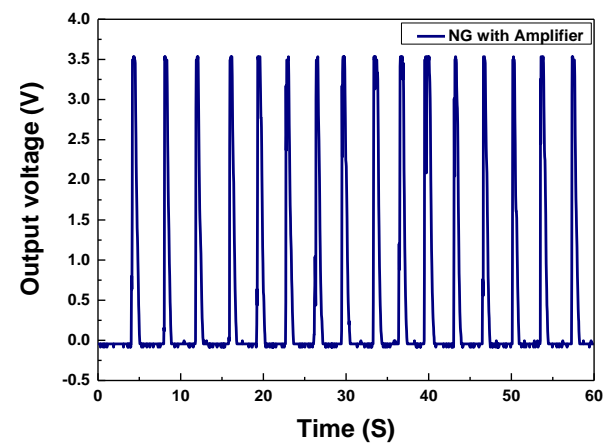

Figure 5-5: (a) Schematic diagram of the complete electronic circuit during measurements, (b) the average output voltage as a function of time under many footsteps when the amplifier is connected to one NG.

In order to transmit a signal from the NG through wireless scenario, a Wireless Sensor Network (WSN) developed at Linköping University has been utilized [7-9]. This WSN is based on a ZigBee specification. The WSN consists of gateway, routers and end devices. The gateway and routers are the mains-powered components and the end devices for sensing are battery-powered. The piezoelectric NG is connected to the end device though an amplifier as shown in Figure 5-5 (a). The end device (wireless transmission node) sends a message, when an event occurs. The message is received by the gateway between the wireless sensor network and the internet and is saved in the cloud. An interrupt should be triggered for the event to occur. It is triggered by the rising edge of the digital signal. The digital signal is considered to be logically 0 when the voltage is lower than $0.5 \mathrm{~V}$ and digital 1 when the voltage is higher than $2.5 \mathrm{~V}$. As the maximum voltage of a single $\mathrm{NG}$ is less than $2.5 \mathrm{~V}$ an amplifier is used to ensure stable operation. An operational amplifier in non-inverting configuration is used to amplify the signal from a single NG by 40 times. Figure 5-5 (b), show that an output voltage of $3.6 \mathrm{~V}$ was obtained.

The fabricated $\mathrm{ZnO}$ NWs piezoelectric NG device shows a possible application as a low-frequency self-powered sensor, with potential applications in wireless sensor networks. 


\subsection{Paper III: Low Frequency Accelerator Sensor Based on Piezoelectric ZnO Nanorods Grown by Low Temperature Scalable Process}

Ambient vibrations are considered as a popular phenomenon that exists in our daily life. It is created due to mechanical disturbances from different sources such as music/sound, noise, engine movement, wind energy etc.. Observing of vibrations has a significant role in sensor technology. It is of interest for monitoring the operation of machines, stability of bridges and buildings, prediction of natural disasters etc.. [10-12]. Potential studies have been performed to develop devices that can harvest energy from vibrations. However, the novelty of our work is in developing a low frequency devices which can be used as sensor for an accelerating systems [13]. In order to harvest low frequency vibrations or noise disturbances created from any mechanical source it is important to develop new devices with special design. The substrate is one of the important design parameters. Plastic as a substrate provides many advantageous, among which, being foldable, and can allow relatively large deformation, retain its shape, etc.. [14-16]. Plastic as a substrate is preferable to use in such harvesting systems. The demonstration of NGs on biodegradable foldable substrates will allows their implantation in human body for sustainable powering of implanted sensors with no need for surgery to remove them.

(a)

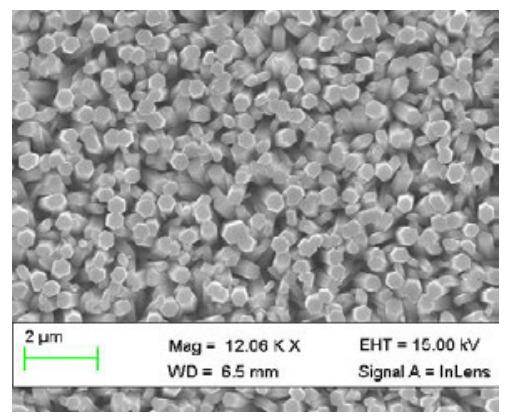

(c)

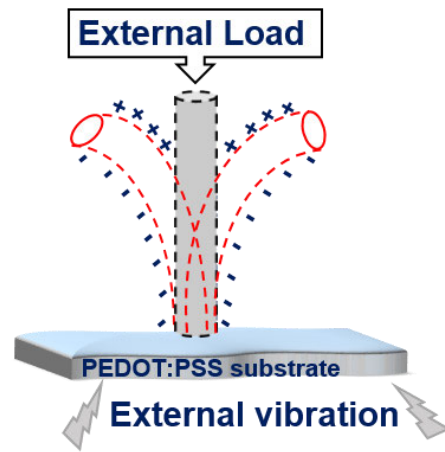

(b)

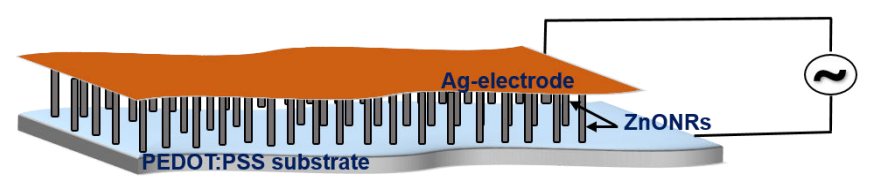

Figure 5-6: (a) Representative SEM image of the ZnO nanorods synthesized on PEDOT:PSS plastic substrate. (b) Schematic diagram showing the flexible NG. (c) Schematic diagram shows where the $\mathrm{ZnO} \mathrm{NR}$ is agitated by an external vibration/load mechanical energy applied through the flexible PEDOT:PSS substrate. 
Piezoelectric vertically aligned ZnO NRs were grown onto a PEDOT:PSS plastic substrate using the scalable low-temperature hydrothermal method as shown in the SEM image of Figure 5-6 (a). Then a NG device was fabricated as shown in the schematic diagram of Figure 5-6 (b). This NG was tested under the influence of low frequency vibrations, in particular different load masses and finger prints pressure were applied as a low frequency sources.

As for the case when bending a NR (Figure 5-6 (c)), the polarization produced by ionic charges of the lattice ions along the vertical NR will result in a voltage appearance in the direction of the external vibrations/pressure forces.

Figure 5-7(a) shows a typical voltage output of the ZnO NRs under the influence of successive cycles of stretching and releasing. The measured output voltage varies from 0.09 to $0.3 \mathrm{~V}$ when $5-41 \mathrm{~Hz}$ frequency has been applied, respectively. While the maximum output power obtained is increased gradually from 0.0903 to $0.092 \mu \mathrm{W}$.

(a)

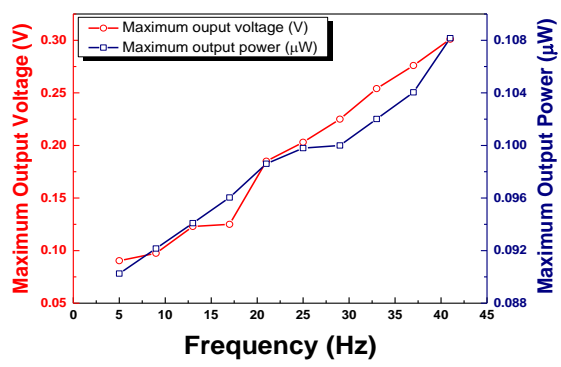

(b)

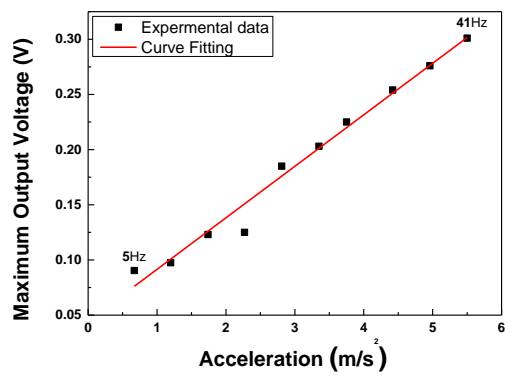

(c)

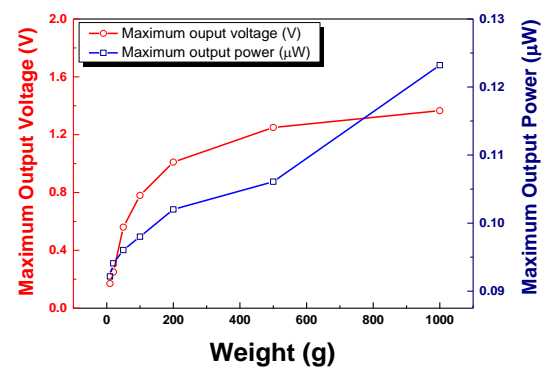

(d)

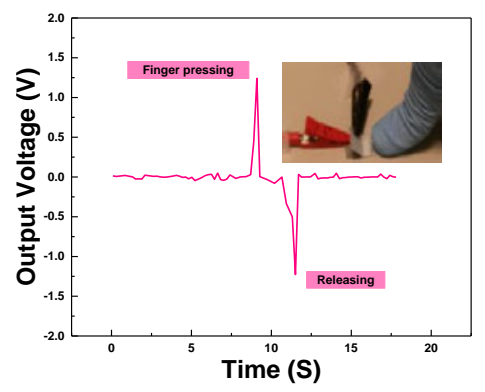

Figure 5-7: (a) The output voltage versus the compressive stress at different low frequencies (5-41 $\mathrm{Hz}$ ). (b) The maximum output voltage as a function of acceleration. (c) The output voltage versus the compressive stress for mass weights of (10-1000 g). (d) Output voltage as function of the pressing and releasing during finger print pressure. The inserts is a digital photograph showing the corresponding finger pressure experiment.

To determine the acceleration, the fabricated sensor was mounted onto a vibrating surface, the piezoelectric potential appearing upon vibrations is then measured [13]. Different low 
frequency tests were performed, and the experimental results show relatively high sensitivity to frequencies as low as $5 \mathrm{~Hz}$. Since the acceleration produces a stress which is proportional the magnitude of the applied acceleration, then the harvested voltage will be proportional to the acceleration. Figure 5-7 (b) shows the relationship between the output voltage and the acceleration along the $\mathrm{x}$-direction. An acceleration range of about $0.67-5.5 \mathrm{~ms}^{-2}$ was obtained for a frequency range of $5-41 \mathrm{~Hz}$, respectively. As can be seen there is a linear correlation. Furthermore, the sensor has a high sensitivity of $0.047 \mathrm{Vs}^{2} \mathrm{~m}^{-1}[13]$.

The second test performed was by applying different weights while recording the output voltage [13]. The response of the NG under a dynamic load was studied using different masses. The NG was deformed by applying manual stress, so that the ZnO NRs experienced a cycling stretching-releasing uniaxial deformation. As the applied stress is gradually increased from 10 to $20,50,100,200,500$ then to $1000 \mathrm{~g}$; the output voltage increases as shown in Figure 5-7 (c). By increasing the deformation magnitude, the harvested output will increase linearly until it saturates. In Figure 5-7 (c), the measured output voltage and power varies from 0.17 to $1.37 \mathrm{~V}$ and 0.0922 to $0.123 \mu \mathrm{W}$ when 10 to $1000 \mathrm{~g}$ masses have been applied, respectively [13].

As a demonstration of utilizing irregular mechanical energy, such as human motion into electricity, our NG was successfully used as a power source without an energy storage system. This NG shows a response when finger pressing was applied. As shown in Figure 5-7 (d), the maximum output voltage exhibited from the NG of about $1.24 \mathrm{~V}$ [13]. The insert Figure shows the NG under finger pressing. Due to the relatively small size of the NRs, such configuration can be used for developing sensitive finger print camera. The finger print experiment was repeated with an extra set up where the actual weigh exerted by the finger print was roughly estimated. This was repeated many times and the results show that the equivalent weight of the finger prints pressure is about 400-500 g. From Figure 5-7 (c) and for an applied weight of $500 \mathrm{~g}$, we observe that the output voltage is $1.25 \mathrm{~V}$. This value is very consistent with the value of the output voltage measured from the weights experiments described above. This observation indicates that the present device results are reproducible. Moreover, this sensor can be used to measure collision acceleration, which has potential practicability in automobile security systems. Since this NG has been demonstrated as able to harvest energy of about $1.24 \mathrm{~V}$ under the pressing of human body finger.

This character shows that our NG is suitable for the challenging low frequency applications. Further the growth process used is scalable and suitable for industrial production. The demonstrated energy harvesting component, is based on low cost bottom up approach. The low cost is due to the synthesis route adopted, i.e. the low temperature aqueous chemical growth. The low temperature allows the utilization of soft substrates, and hence components suitable for harvesting energy from human body for example can be developed. This can be of interest for powering implanted devices, sensitive finger print camera etc.. [13]. 


\subsection{Paper IV: A flexible Anisotropic Self-powered Piezoelectric Direction Sensor Based on Double Sided $\mathrm{ZnO}$ Nanowires Configuration}

Continuing with the flexible plastic substrates, we demonstrated a piezoelectric NG with constructed layers of $\mathrm{ZnO} \mathrm{NWs}$ grown on the both sides of flexible PEDOT:PSS plastic substrate (see Figure 5-8 (a)) [16]. The NG output resulting from mechanical deformation can be used either as electric output electric power, or as a sensor for detecting the magnitude and/or the rate of any mechanical deformation [16].

When the NG sample is bended, the ZnO NWs on one side will be stretched while they will be compressed on the other side. A piezopotential will then be produced on both sides. This is illustrated in Figure 5-8 (b). The observation of harvested voltage from different sides of this configuration is expected to be different voltage polarities. When bending the two different sides they will be either stretched or compressed. This difference between stretching and compressing would produce different voltage polarity. The results are shown in Figure 58 (c and d) [16]. Indeed upon bending, this configuration provided a self-powered anisotropic direction sensor.

(a)

(b)
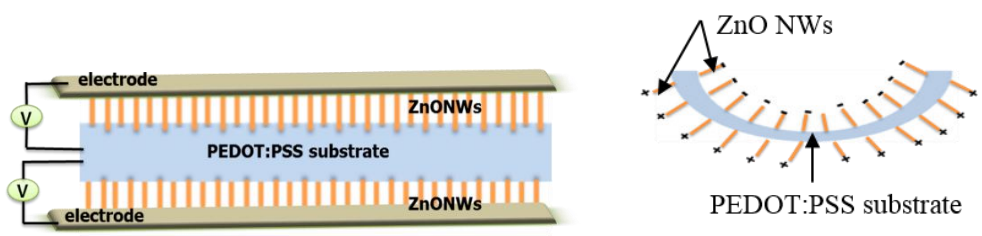

(c)

(d)
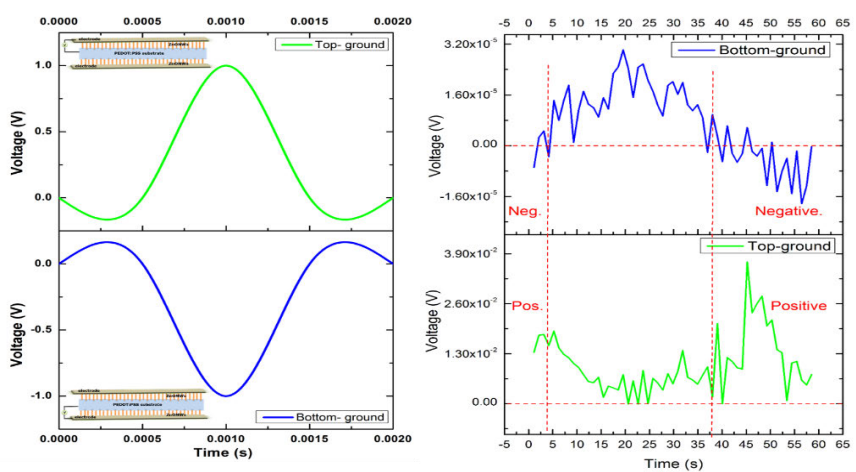

Figure 5-8: (a) Schematic diagram showing a double sided NG. (b) The polarity of the output voltages under bending for case of the downward bending. (c) The measured output voltage for a period of millisecond obtained from the top side NWs (green) and bottom side (blue), the inserts show the corresponding measurement side. (d) The generated output voltage from both sides during compressing and releasing for a period of about $60 \mathrm{~s}$. 
A digital storage oscilloscope DSO-X 2012A was used to measure the output voltage at low frequency when bending the device [16]. Both the top and bottom $\mathrm{ZnO}$ NWs have led to a harvested voltage of $+1 \mathrm{~V}$ and $-1 \mathrm{~V}$, respectively as shown in Figure 5-8 (c).

When applying a downward bending the top side (with bending angle approximately from $30^{\circ}$ to $45^{\circ}$ ) has a compressive strain with positive charge polarity at the top of the NWs, while the bottom side has a tensile strain leading to negative charge polarity at the top of the NWs on the bottom side. So when the NGs is under bending followed by releasing, the response of the output voltage vary between positive and negative polarity for the top and bottom sides, respectively, as shown in Figure 5-8 (d).

(a)

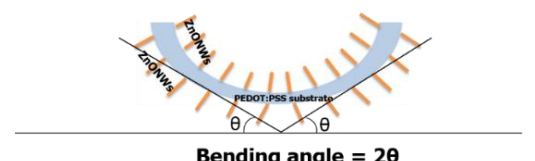

Bending angle $=\mathbf{2 \theta}$

(b)

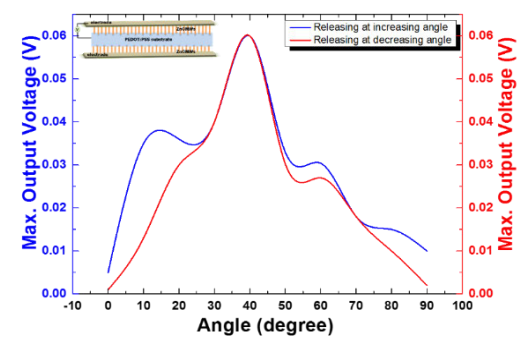

(c)

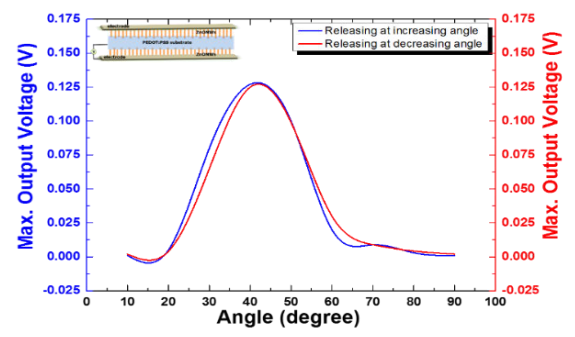

(d)

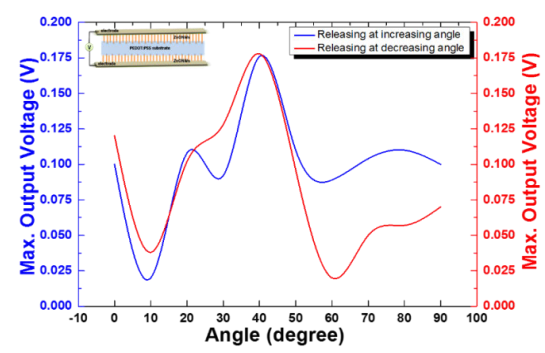

Figure 5-9: (a) Schematic diagram showing the bending angle measurement configuration. (b-d) The maximum output voltage as a function of the bending angle (from $0^{\circ}$ to $90^{\circ}$ ) for the different connections as shown in the inserts of each curve.

The harvested power from each side was found to increase and at a certain angel, it then saturates. Increasing the angel to higher value leads to decrease the harvested voltage. This is shown in Figure 5-9 (a-d). The fact that one side will be compressed while the other will be stretched will imply that anisotropic voltage will simultaneously be observed [16].

To investigate the effect of the substrate, a $\mathrm{NG}$ based on $\mathrm{ZnO} \mathrm{NWs}$ grown hydrothermally on a flexible silver coated plastic substrate is fabricated. The obtained results confirmed that there was no pronounced difference in the piezoelectric harvested energy to be noted. The energy harvested under different bending angles for the two devices configurations generated 2.0 V and 1.5 V, from the PEDOT: PSS and silver coated plastic, respectively [16]. 
(a)

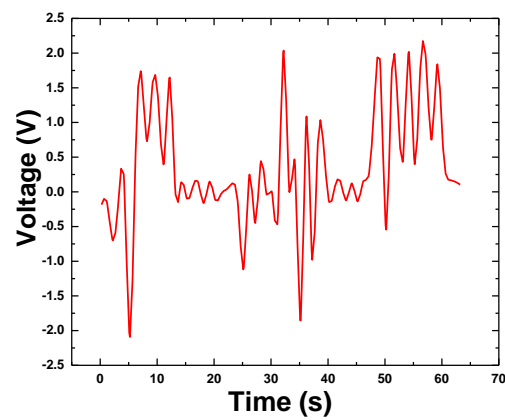

(b)

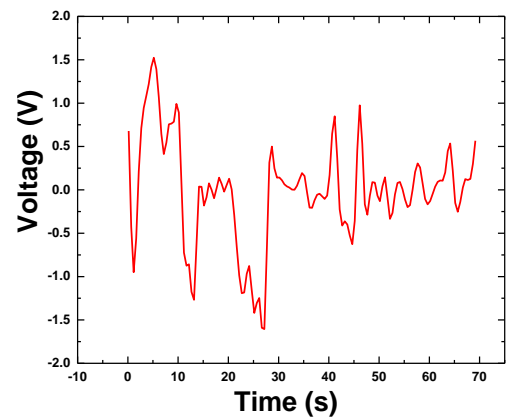

Figure 5-10: The instantaneous output voltages of the NG based on (a) PEDOT:PSS, and (b) silver coated plastic substrates.

The obtained promising results from the double sided NG indicated a potential for different applications, e.g. in sensing, security application etc.. [16].

\subsection{Paper V: A Flexible Sandwich Nanogenerator for Harvesting Piezoelectric Potential from Single Crystalline Zinc Oxide Nanowires}

Here, we present a different sandwiched nanogenerators (NGs) based on $\mathrm{ZnO}$ NWs grown hydrothermally on plastic substrate (silver and gold coated). The fabricated NGs devices set to observe the output when a mechanical deformation load is applied [17].

(a)

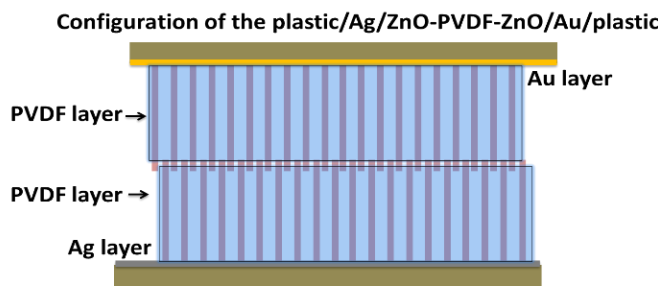

(b)

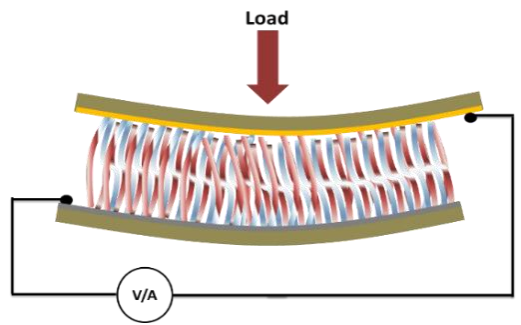

Figure 5-11: (a) ZnO NWs grown on $\mathrm{Ag}$ and $\mathrm{Au}$ substrates. (b) Shows the application of external force to the surface of the NG configuration.

The three fabricated configurations with different designs and the harvested energy when applying external force was measured, as shown in Figure 5-11(a-b). Different polarity peaks of the generated voltage and current vary due to the pressing and releasing of the plasticbased NGs. When a heavy object causing a force of $0.05 \mathrm{~N}$ was in contact with the NG, a 
force is applied on the surface. This pressure/force will generate a piezoelectric potential due to the compressive strain, as shown in Figure 5-12 (a-f). A potential output with a maximum value of $2.4 \mathrm{~V}$ and a current of $152.2 \mu \mathrm{A}$ was obtained. The maximum value was achieved from the third configuration with face to face $\mathrm{ZnO} N W$ s configuration with inserted PVDF in between [17].

(a)

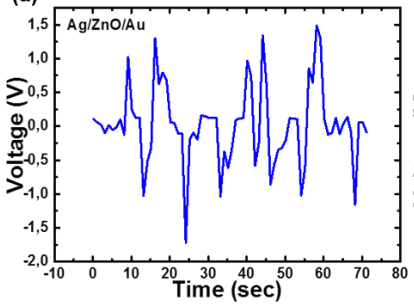

(b)

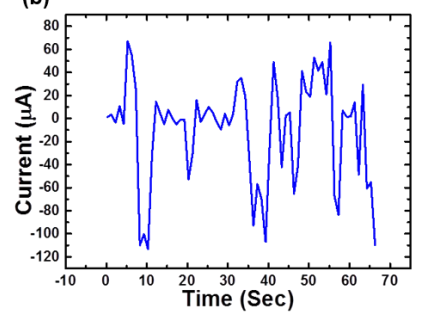

(c)

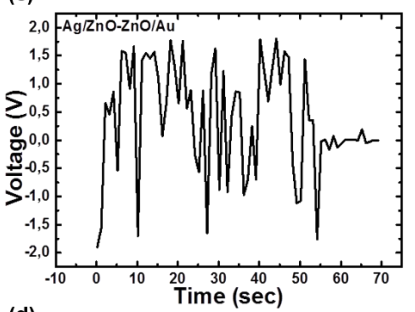

(d)

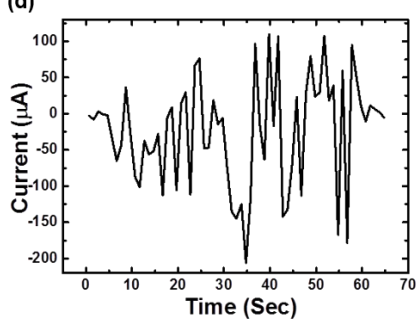

(e)

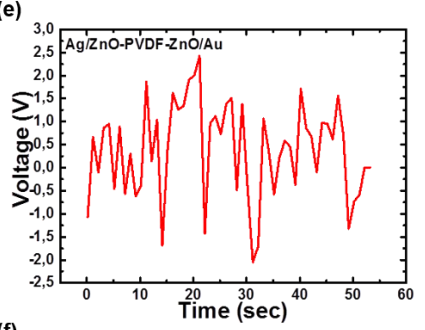

(f)

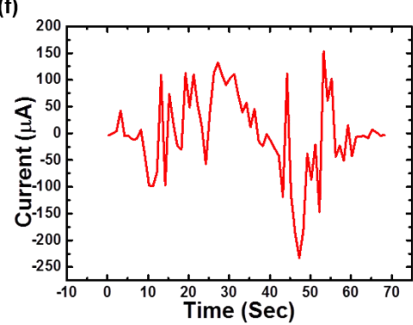

Figure 5-12: Measurement of the piezoelectric potential and the corresponding current by open circuit and short circuit measurements from the three configurations: (a-b) $\mathrm{Ag} / \mathrm{ZnO} \mathrm{NWs} / \mathrm{Au}$, (c-d) $\mathrm{Ag} / \mathrm{ZnO}$ NWs-ZnO NWs/Au, and (e-f) Ag/ZnO NWs-PVDF-ZnO NWs/Au.

The three configuration yielded three different results. This indicates the impact of the sandwiched configuration on the output magnitude [17].

The principle and the sandwiched NG demonstrated the basis for new self-powering nanotechnology that can be utilized for harvesting relatively large amount of electrical energy from the environment to be utilized for many applications.

\subsection{Paper VI: Piezoelectric and Opto-electrical Properties of} Silver-Doped $\mathrm{ZnO}$ Nanorods Synthesized by Low Temperature Aqueous Chemical Method

When the $\mathrm{ZnO}$ is doped with different impurities, $\mathrm{ZnO}$ properties like e.g. electrical, optical, mechanical etc. will all be altered and its room temperature opto-electronic and ferromagnetic behavior are modified. This will lead to the use of the new combination as promising material for optoelectronics and spintronic efficient sensor technology [18]. 
With this observation, we have synthesized $\mathrm{Zn}_{1-\mathrm{x}} \mathrm{Ag}_{\mathrm{x}} \mathrm{O}$ NRs ( $\mathrm{x}=0,0.03,0.06$, and 0.09) via the hydrothermal method at low temperature on silicon substrate. The (111) Ag diffraction peak (from the substrate), the $\mathrm{x}$-ray diffraction spectra of the different $\mathrm{Zn}_{1-\mathrm{x}} \mathrm{Ag}_{\mathrm{x}} \mathrm{O}$ NRs ( $\mathrm{x}=$ 0, 0.03, 0.06 and 0.09), samples show diffraction peaks corresponding to the $\mathrm{ZnO}(002)$, (100) and (101) planes. The (002) reflection peak is intense and sharper in nature, as compared to other peaks, showing a preferential c-axis growth orientation for all the NRs (see Figure 5-13 (a)). Nevertheless its intensity is decreasing with increasing the $\mathrm{Ag}$ concentration. Increasing the concentration of $\mathrm{Ag}$ leads to decrease the crystal quality of the $\mathrm{ZnO}$ NRs, in agreement with previous results reported [19]. Figure 5-13 (b) shows the XRD patterns of the (002) diffraction peaks for all samples. In this Figure there is also a clear slight shift of the angular position of the (002) peak. This shift shows that the Ag ions substituted the $\mathrm{Zn}$ atoms in the $\mathrm{ZnO}$ NRs crystal matrix. Additionally and because the radius of $\mathrm{Ag}^{2+}$ ion $(1.22 \mathrm{~A})$ is a greater than that of $\mathrm{Zn}^{2+}$ ion $(0.72 \mathrm{~A})$, the increase of the number of $\mathrm{Ag}^{2+}$ ion in the $\mathrm{Zn}$ ions lattice sites contraction the lattice parameter.

(a)

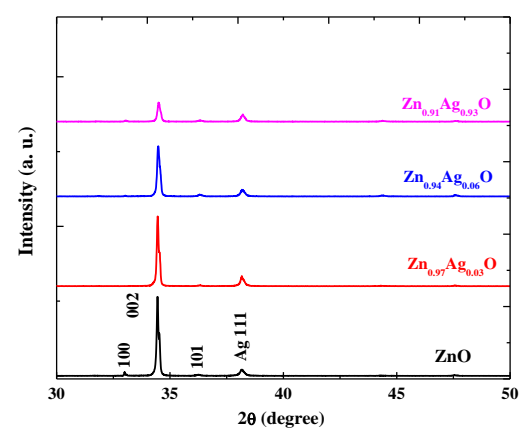

(b)

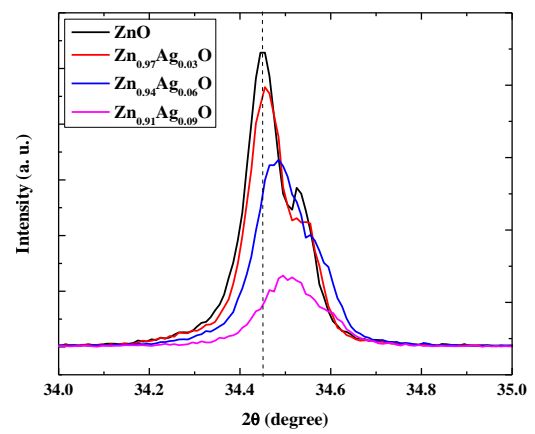

(c)

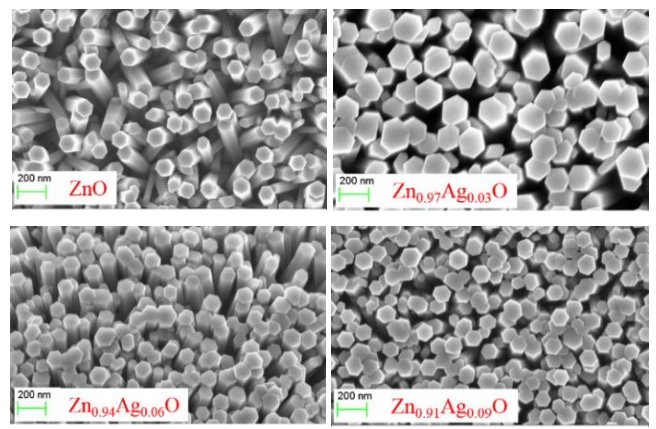

Figure 5-13: (a) XRD patterns for all the $\mathrm{Zn}_{1-\mathrm{x}} \mathrm{Ag}_{\mathrm{x}} \mathrm{O}$ NRs grown on silicon substrate ( $\mathrm{x}$ value is as indicated). (b) The XRD patterns of the (002) diffraction peaks. (c) SEM image of all the silver doped $\mathrm{Zn}_{1-\mathrm{x}} \mathrm{Ag}_{\mathrm{x}} \mathrm{O}$ NRs grown on silicon substrate ( $\mathrm{x}$ value is as indicated). 
X-ray photoelectron spectroscopy (XPS) results indicated the existence of $\mathrm{Ag}$ in the $\mathrm{ZnO}$ crystal lattice, as shown in Figure 5-14 (a). This Figure shows the XPS spectra of the Ag 3d peaks ( $\mathrm{Ag} 3 \mathrm{~d}_{5 / 2}$ and $\mathrm{Ag} 3 \mathrm{~d}_{3 / 2}$ ) for the pure $\mathrm{ZnO}$ (pink), $\mathrm{Zn}_{0.97} \mathrm{Ag} 0.03 \mathrm{O}$ (red), $\mathrm{Zn}_{0.94} \mathrm{Ag}_{0.06} \mathrm{O}$ (blue) and $\mathrm{Zn}_{0.91} \mathrm{Ag}_{0.09} \mathrm{O}$ NRs (black). For the three doped samples, the XPS signal from $\mathrm{Ag}$ $3 \mathrm{~d}$ photoemission was substantially detected, for instance the peak of $\mathrm{Ag} 3 \mathrm{~d}$ in the $\mathrm{Zn}_{0.91} \mathrm{Ag}_{0.09} \mathrm{O}$ NRs sample appears at around $368.12 \mathrm{eV}$ and $374.17 \mathrm{eV}$ for $\mathrm{Ag} 3 \mathrm{~d}_{5 / 2}$ and Ag $3 d_{3 / 2}$, respectively. Therefore, these spectra clearly confirm the incorporation of Ag into the $\mathrm{ZnO}$ crystal lattice. The overall observed XPS spectra of $\mathrm{Zn}_{1-\mathrm{x}} \mathrm{Ag}_{\mathrm{x}} \mathrm{O}$ NRs were in agreement with earlier reports [19-23].

(a)

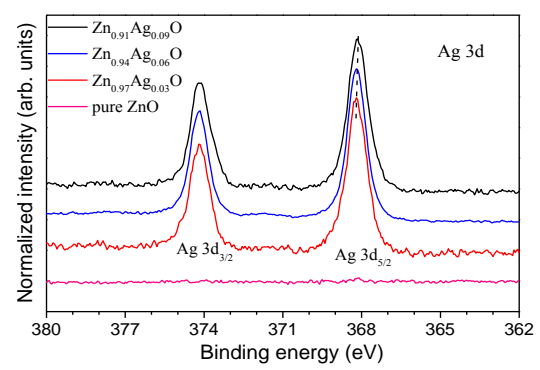

(b)

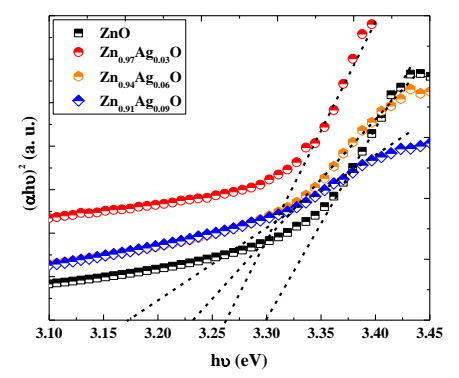

Figure 5-14: (a) XPS spectrum of $\mathrm{Ag} 3 \mathrm{~d}$ peaks for the $\mathrm{Zn}_{1-\mathrm{x}} \mathrm{Ag}_{\mathrm{x}} \mathrm{O}$ NRs grown on silicon substrate (x value is as indicated). All XPS peaks were normalized. The dashed line indicates the change of the Ag peak position with doping. (b) Plot of $(\alpha \mathrm{h} v)^{2}$ versus $\mathrm{h} v$ of the $\mathrm{ZnO}$ (black), $\mathrm{Zn}_{0.97} \mathrm{Ag}_{0.03} \mathrm{O}$ (red), $\mathrm{Zn}_{0.94} \mathrm{Ag}_{0.06} \mathrm{O}$ (orange) and $\mathrm{Zn}_{0.91} \mathrm{Ag}_{0.09} \mathrm{O}$ NRs (blue).

The optical band gap of the $\mathrm{Zn}_{1-\mathrm{x}} \mathrm{Ag}_{\mathrm{x}} \mathrm{O}$ NRs ( $\mathrm{x}=0,0.03,0.06$ and 0.09 ) samples was determined using the Tauc method as shown in Figure 5-14 (b). With increase in the amount of Ag doping, the density of states of these dopants increase and form a continuum of states just like in the bands, and the band gap is effectively decreased. In the present thesis, the values of optical band gap for the $\mathrm{Zn}_{1-\mathrm{x}} \mathrm{Ag}_{\mathrm{x}} \mathrm{O}$ NRs ( $\mathrm{x}=0,0.03,0.06$ and 0.09$)$ samples are shown in Figure 14 (b), calculated by the extrapolation method. The values obtained were $3.30 \mathrm{eV}$ (black curve), $3.26 \mathrm{eV}$ (red curve), $3.22 \mathrm{eV}$ (orange curve) and $3.17 \mathrm{eV}$ (blue curve), for the different $\mathrm{Zn}_{1-\mathrm{x}} \mathrm{Ag}_{\mathrm{x}} \mathrm{O} \mathrm{NRs}$ ( $\mathrm{x}=0,0.03,0.06$ and 0.09) samples, respectively. As it can be seen, the optical band gap decreased by increasing the amount of the Ag doping. This might be an indication that the Ag has substituted the $\mathrm{Zn}$ in the lattice. This is consistent with the observation from the $\mathrm{x}$-ray results discussed above. So one can say that the optical band gap of Ag doped $\mathrm{ZnO}$ nanostructures depends on the lattice sites of $\mathrm{Ag}$ in the $\mathrm{ZnO}$ [18].

The effective piezo-response of our samples was calculated using data obtained from nanoindentation measurements, where samples with varying Ag content were compared, for measuring both the direct and converse piezoelectric effects [19]. 
Starting with the direct effect, Figure 5-15 (a) show a graphical representation of the nanoindentaion test for the direct piezoelectric effect. The piezoelectric potential generated values from pure sample of $\mathrm{ZnO} \mathrm{NRs}$ and $\mathrm{Zn}_{0.97} \mathrm{Ag}_{0.03} \mathrm{O}$ NRs were decreased from $7 \mathrm{mV}$ to 2 $\mathrm{mV}$, respectively as shown in Figure 5-15 (b).

After that, converse piezoelectric effect was investigated by nanoindentation as shown in Figure 5-15 (c). The value of the piezoelectric coefficient ( $\left.\mathrm{d}_{33}^{\text {eff }}\right)$ was found to decrease from $130 \mathrm{pm} / \mathrm{V}$ to $8.75 \mathrm{pm} / \mathrm{V}$ for the pure $\mathrm{ZnO} \mathrm{NRs}$ and $\mathrm{Zn}_{0.97} \mathrm{Ag}_{0.03} \mathrm{O}$ NRs, respectively as clearly shown in Figure 5-15 (d). However, in this Figure, upon further increase of the Ag fraction the piezoelectric coefficient has slightly decreased [18].

(a)

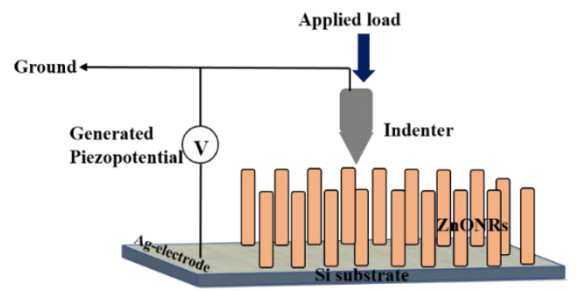

(b)

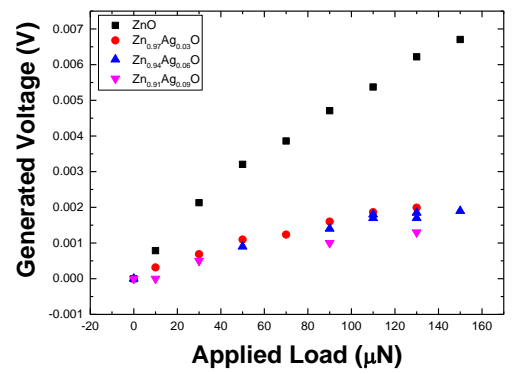

(c)

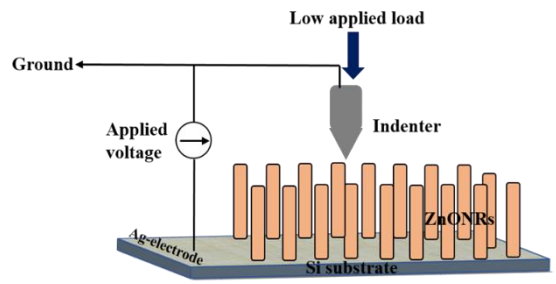

(d)

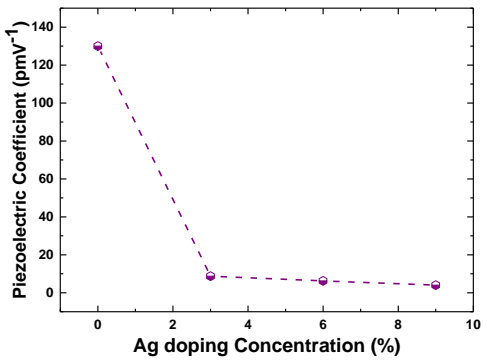

Figure 5-15: (a) Graphical representation of the nanoindentaion test for the direct piezoelectric effect. (b) Generated piezoelectric potential as a function of the applied load. (c) Graphical representation of the nanoindentaion test for the converse piezoelectric effect. (d) Piezoelectric coefficient as a function of the doping concentration.

By introducing a very small doping amount, the effect will be such that; this dopant addition distorts the unit cell of the $\mathrm{ZnO}$ crystal. If the doping level is further increased, there will be a high deformation of the crystalline structure, leading to loss of the symmetry and decreasing thereafter the piezo response [18].

This result confirms that $\mathrm{Ag}$ doped $\mathrm{ZnO}$ is not appropriate for piezoelectric energy harvesting devices. Also these results indicated that, even preserving the crystallinity and electrical resistivity of the $\mathrm{Ag}$ doped $\mathrm{ZnO} \mathrm{NRs}$, the material is not suitable for piezoelectric device applications [18]. 


\subsection{References}

[1] Z. L. Wang, G. Zhu, Y. Yang, S. Wang, C. F. Pan, Mat. Tod., 15 (2012) 532.

[2] B. Tian, X. Zheng, T. J. Kempa, Y. Fang, N. Yu, G. Yu, J. Huang, C. M. Lieber, Nat., 449 (2007) 885.

[3] Z. L. Wang, Sci. Am., 298 (2008) 82.

[4] C. Pan, H. Wu, C. Wang, B. Wang, L. Zhang, Z. Cheng, P. Hu, W. Pan, Z. Zhou, X. Yang, J. Zhu, Adv. Mat., 20 (2008) 1644.

[5] E. S. Nour, M. O. Sandberg, M. Willander, O. Nur, Nano Ene., 9 (2014) 221.

[6] E. S. Nour, A. Bondarevs, P. Huss, M. Sandberg, S. Gong, M. Willander, O. Nur, Nanoscale Res. Lett., 11 (2016) 156.

[7] P. Huss, N. Wigertz, J. Zhang, A. Huynh, Q. Ye, S. Gong, Adv. Sci. and Techn. Lett., 41 (2013) 1.

[8] P. Huss, N. Wigertz, J. Zhang, A. Huynh, Q. Ye, S. Gong, Inter. Jou. of Fut. Gen. Comm. and Networ., 7 (2014) 235.

[9] A. Bondarevs, P. Huss, S. Gong, O. Weister, R. Liljedahl, Sens. and Transducers Jou., 192 (2015) 16.

[10] Y. Itakura, N. Fujii, and T. Sawada, Phys. Chem. Earth B, 25 (2000) 717.

[11] E. P. James, M. J. Tudor, S. P. Beeby, N. R. Harris, P. Glynne- Jones, J. N. Ross, N. M. White, Sens. Actuators A, 110 (2004) 171.

[12] K. Fischer and S. G. Mayr, Adv. Mat., 23 (2011) 3838.

[13] E. S. Nour, C. O. Chey, M. Willander, O. Nur, Phy. Sta. Sol., 26 (2016) 095502.

[14] X. D. Wang, J. H. Song, J. Liu, Z. L. Wang, Sci., 316 (2007) 102.

[15] I. Dakua N. Afzulpurkar, Nanomat. and Nanotech., 3 (2013) 2013.

[16] E. S. Nour, C. O. Chey, M. Willander. O Nur, Nanotech., 26 (2015) 095502.

[17] E. S. Nour, A. Khan, M. Willander, O. Nur, Nanomat. and Nanotech., 4 (2014) 24.

[18] E. S. Nour, A. Echresh, X. Liu, E. Broitman, M. Willander, O. Nur, AIP Adv., 5 (2015) 077163.

[19] L. Xu, G. Zheng, L. Zhao, S. Pei, Jou. of Lumin., 158 (2015) 396.

[20] K. Kim, D-H. Lee, S. Y. Lee, G-E. Jang, J-S. Kim, Nanoscale Res. Lett., 7 (2012) 273.

[21] R. Chen, C. Zou1, J. Bian, A. Sandhu, W. Gao, Nanotech., 22 (2011) 105706.

[22] O. A. Yıldırım, H. E. Unalan, C. Durucan, J. Am. Ceram. Soc., 96 (2013) 766.

[23] T. N. Ravishankar, K. Manjunatha, T. Ramakrishnappa, G. Nagaraju, D. Kumar, S. Sarakar, B. S. Anandakumar, G. T. Chandrappa, V. Reddy, J. Dupont, Mat. Sci. in Semicond. Processing, 26 (2014) 7 . 


\section{Chapter six: Summary and future prospective}

\subsection{Research summary}

Zinc oxide $(\mathrm{ZnO})$ is considered as a semiconducting material with special importance. This is due to its unique and promising various nanostructures morphologies combined with the fact that it is also, biocompatible and bio safe. Therefore, research interest about $\mathrm{ZnO}$ is increasing and different applications can are being demonstrated, such as in optics, optoelectronics, sensors, actuators, energy, biomedical sciences and spintronics, are some examples of the applications demonstrated [1]. Furthermore, the inherent piezoelectric property of $\mathrm{ZnO}$, combined with other properties like the variety of nanostructures morphologies, the possibility to synthesize it by cost effective methods, makes $\mathrm{ZnO}$ an interesting material with potential for developing innovative devices [1].

Different types of $\mathrm{NGs}$ based on $\mathrm{ZnO}$ nanostructures have been intensively developed, and studied for testing under different kinds of low frequency mechanical deformation. Well aligned $\mathrm{ZnO}$ nanowires (NWs) possessing high piezoelectric coefficient were synthesized on flexible substrates using the low temperature hydrothermal route. These $\mathrm{ZnO}$ NWs were then used in different configurations to demonstrate different low frequency energy harvesting devices. However using piezoelectric $\mathrm{ZnO} \mathrm{NWs}$, we started with the fabrication of sandwiched NG with hand writing enabled energy harvesting device based on a thin silver layer coated paper and plastic substrates (paper I). Such device configurations can be used for the development of electronic programmable smart paper. Further, we developed this NG to work as a triggering sensor for wireless sensor system using foot-step pressure (paper II). The fabricated ZnO NWs piezoelectric NG device shows a possible application as a low-frequency self-powered sensor, with potential applications in wireless sensor networks. After that, we investigated and fabricated a sensor on PEDOT: PSS plastic substrate either by one sided growth technique (paper III) or by using double sided growth (paper IV). For the first growth technique, the fabricated sensor has been used for an acceleration system; while the fabricated sensor by the second technique has worked as an isotropic directional sensor. This fabricated configuration demonstrates stability in sensing and hence the suitability and potential for applications in security and surveillance systems. In addition to that, we investigated the fabrication of sandwich nanogenerator on plastic substrates (paper V). Finally, we investigated how doping tune the $\mathrm{ZnO}$ properties (paper VI). This is done by studying the piezoelectric and opto-electrical properties of silver-doped $\mathrm{ZnO}$ nanorods synthesized by the low temperature aqueous chemical method.

\subsection{Future prospective}

Despite the greatest deal of efforts devoted to develop energy harvesting devices that function efficiently at low frequencies, more investigations are desired on the design, developing highquality nanomaterial routines and to develop mature device fabrication steps in order to achieve nano-devices with acceptable reliable performance to demonstrate efficient energy harvesting systems. Further, such system should be cost-effective and compatible with scale- 
up industrial mass production possibility to satisfy the large need of the newly emerging selfpowered systems. Recently, research in triboelectric nanogenerator (TENG) for harvesting mechanical energy is considered as prospective approach. This due to the features of soft nature, low cost, large output with efficient energy conversion [2]. 


\subsection{References}

[1] L-W. Yamin, Wiley-ISTE, 1 (2015).

[2] Y. Yao, T. Jiang, L. Zhang, X. Chen, Z. Gao, Z. L. Wang, ACS Appl. Mat. Interfaces, 8 (2016) 21398. 


\section{Papers}

The articles associated with this thesis have been removed for copyright reasons. For more details about these see:

http://urn.kb.se/resolve?urn=urn:nbn:se:liu:diva-131858 